\title{
La economía social desde el institucionalismo económico. Evidencia empírica
}

\author{
Miguel Ángel Alarcón Conde
}

\section{RESUMEN}

La intención del trabajo es ofrecer una definición de Economía Social en sentido amplio desde principios del Institucionalismo Económico. Así, elementos como la persistencia en el hábito de la No Prioridad en el Ánimo de Lucro Personalista y las rutinas ejercidas por las entidades de la categoría, como son las Transferencias Sociales en Especie, resultan ser principios comunes a todas las entidades que componen la definición generalmente aceptada por los estudiosos del tema: la sugerida por el CIRIEC Internacional, ya recogida en la Carta de la Economía Social de la CEP-CEMAF en 2002, extensible a otras perspectivas inclusivas de actividades económicas que elevan valores humanos en nuestra sociedad.

PALABRAS CLAVE: Economía Social, Tercer Sector, Nuevo Institucionalismo Económico, Teoría de Grafos, Ontología del lenguaje.

CLAVES ECONLIT: B52, L30, P13, P50.

Cómo citar este artículo / How to cite this article: ALARCÓN CONDE, M.A. (2016): "La economía social desde el institucionalismo económico. Evidencia empírica", CIRIEC-España, Revista de Economía Pública, Social y Cooperativa, 86, 61-100.

Correspondencia: Miguel Ángel Alarcón Conde, Universidad de Castilla-La Mancha.

E-mail: Miguelangel.alarcon@uclm.es. 


\section{EXPANDED ABSTRACT}

\section{The Social Economy: an Economic Institutionalism Approach. Empirical evidence}

\section{Objectives}

To propose a definition of the Social Economy in a broad sense, based on principles of Economic Institutionalism. Thus, elements such as the habit of Non-Persistence in Personalist Profit Motive (henceforth, NPPPM), and the routines exercised by the bodies that make up the category which is the object of study, such as Social Transfers in Kind (henceforth, STKs), seem to be common principles that satisfy the definition generally accepted by academics: namely the one suggested by CIRIEC International.

To show evidence regarding the existence of STK routines which are the practical consequence of the NPPPM principle.

To demonstrate the lower intensity of the principle of cumulative causality in the case of cooperatives with respect to traditional capitalist bodies, between 2000 and 2012 in the Spanish case.

\section{The methodological design}

The proposal for the definition of the Social Economy is based on principles based on the modern focus of Economic Institutionalism and Graphs Theory and Social Networks Analysis tools, both of which are aided by ideas from Ontology of Language by Echeverría (2008).

Defourny (1992) suggested identifying what distinguishes Social Economy bodies from other organizations as clearly as possible. The diversity of legal languages (of significances and meanings) and sociocultural contexts in different places are obstacles that can be surpassed if it is considered that language is an inseparable part of man, that it exists in order to make it possible to explain human behaviours, and that it is the reason for being of human organizations.

The New Economic Institutionalism (G. Hodgson) can sustain an encompassing Social Economy concept; it maintains continuity with the main contributions of the Original Economic Institutionalism, and assumes that institutions are the uses, customs, norms, routines, or rules by which social and economic relationships between the members of a group are governed. Said categories can evolve to become formal institutions (for example, organizations, norms, and laws, among others). 
Thus, proposition P1, which requires axioms A1, A2, and A3, definitions D1, D2, and D3, and assumptions $\mathrm{S} 1$ though $\mathrm{S} 4$, is demonstrated.

Proposition 1. Social Economy bodies are institutions formed by networks of individuals which make up a typology of relationships based on a common core of empathy and solidarity, both of which are human actions taken to achieve their goals. They can form graphs as long as they are networks.

Definition 1. $A$ graph $G$ is an ordinated pair $G=(V, E)$, where $V$ is a set of vertices or nodes and $E$ is a set of ties and links that relate these nodes. The graph is focussed when there are edges that have an origin and a destination.

Thus, without needing to include qualitative variables, attributes, or quantitative variables, the relationships between individuals in a group would be represented by a set of edges between the nodes of the group, "from" and "to" it, as well.

Four assumptions are considered. Assumption 1, the bodies of the Social Economy can be formalized into graphs where the edges are the means or relationships with which the individuals (nodes) act in order to achieve certain ends. Assumption 2, the means or relationships between individuals are the formalization of habits, rules, or routines; in other words, of theoretical (abstract) institutions. Assumption 3 , the cause of the formal institutions or organizations is the evolutionary dynamic of the theoretical, abstract, institutions. Assumption 4, empathy and solidarity are representatives of relationships or means and, therefore, representable as edges or nexus between the individuals that belong to a network.

Axiom 1. Language is an institution, a regularity of the habit of human communication, and semantics is a rule of language. Consequently, it is an institution that is necessary for the processes of knowledge, learning and advancement. Therefore, it is necessary for building arguments regarding what institutions are.

Axiom 2. The behaviour of the individual is characterized by regularities such as habits, rules, and routines (for groups of individuals) which can be explicit, like organizations or norms, or could be abstract, like cognitive field values.

Axiom 3. The constitution of an organization is formalized from habits, individual values, and rules, but these do not guarantee its survival.

In consequence, the formal guarantee of institutions occurs in accordance with the legal norms current in a society. A legal person may become legally established and not be loyal to its founding principles nor to the current legislation that affects it. The opposite would, however, lead to its own extinction. 
Definition 2, organizations are formal institutions and groups of individuals constituted because of a certain relationship defined among them, as well as because of the relationships between organizations, or between organizations and other individuals. These are made effective from individual habits and they exercise routines.

To pinpoint the relationships between groups of individuals (in or with), we need Definition 3: a clique is a subgroup of a network where the nodes are mutually closer and more strongly connected than with respect to the rest of the members of the network.

Consequently, it is possible to represent the graphs of the five formal institutions which are representative of the Social Economy in Spain (Graph 1). The blue edges represent empathy or solidarity between individuals, the borders and black lines exogenous relationships.

\section{Graph 1. General mechanism for cooperation in the Social Economy}

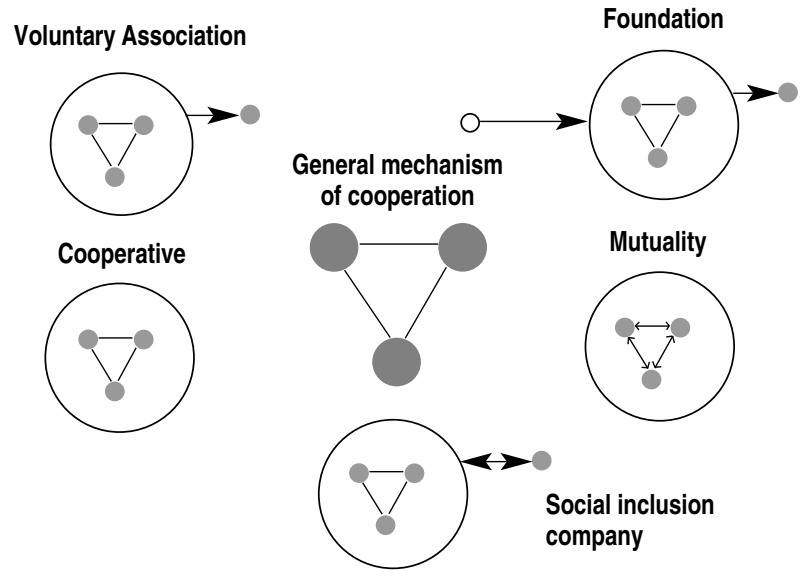

SOURCE: Prepared by the author.

Lemma 1: There is an intersection between the symbols that represent the bodies of the social economy, based on a clique of relationships of empathy or solidarity. Consequently, it is possible to broadly define this common quotient of the group. 


\section{Results}

The possibility of an encompassing definition of the Social Economy indicates that STKs imply a liberation of resources and certain social savings by quantifying missions traditionally assigned to the public sector. The evidence for Spain between 2001 and 2005 estimates the value of the time dedicated by volunteer work to be between 4.9 and 6.8 billion (thousand million) Euros, 0.75 percent of the Spanish GDP.

Spanish cooperatives delivered an annual average of 50 million Euros between 2000 and 2008, based on the differences between the average salary paid by cooperatives that have maintained or increased their work, and that employed by the general economy per productive branch, broadened to STKs.

Finally, there is a different intensity in "cumulative causality principle" between the general economy (mostly capitalist) and cooperatives. Between 2000 and 2007, non-cooperative undertakings intensified in the general economy, because of they was more open to the game of competition and economic profitability, and participations related to cooperativism were seen to fall; thus, cooperative employment grew less than the general employment of the economy. Between 2008 and 2012, the destruction of employment in the population of the Spanish economy was far greater than that of the cooperative economy: -4.4 percent versus the -0.9 percent cumulative average growth rate.

In the end, the Social Networks Analysis indicates that the density of the network of inter-sector relationships in the general economy is greater than that of the cooperative network. Furthermore, it decreased between 2000 and 2008, while that of cooperativism increased because it adapts to the current productive model, but polarizes the productive activity less because it acts under the NPPPM principles, explaining the softening of the recessive cycle, and complements the group of undertakings. 


\section{1.- Introducción}

El trabajo tiene la intención de proponer la categoría de Economía Social desde el Institucionalismo Económico Contemporáneo, y para tal fin se utilizan elementos y principios de la teoría de redes y grafos, con ayuda de cierta ontología del lenguaje, en tanto que la Economía Social es un fenómeno humano y el lenguaje encierra la explicación de su ser y el ser de los fenómenos que observa, siguiendo a Echeverría (2008); de tal manera que se interpreta la Economía Social como un conjunto de relaciones persistentes de empatía (entre humanos, redes de hábitos, instituciones), formalizadas en entidades productoras de bienes y servicios que tienen como principio común la no prioridad en el ánimo de lucro personal (hábito) y son emisoras de transferencias sociales en especie (rutinas). Los componentes del sector, en consecuencia, tienen una prioridad de valores altruistas, filantrópicos, cooperativistas, mutualistas y de promoción de inclusión socioeconómica y laboral, por encima del beneficio pecuniario de finalidad personal.

El trabajo se glosa como sigue. Dos apartados de corte teórico plantean la antesala de las cuestiones a desarrollar, centradas en ciertas causas de las limitaciones en los intentos de medición de la Economía Social -medir para conocer-, donde se concluye la necesidad de definirla, siquiera, en sentido amplio. El primero introduce su consideración contemporánea; el segundo señala los principios a las que se ajusta la definición que se propone, para continuar explicando sus fundamentos. A continuación, se ofrece cierta evidencia sobre Transferencias Sociales en Especie emitidas por las cooperativas españolas, como principio constitutivo de la Economía Social como institución. Seguidamente, se discute sobre tales principios y se ofrece cierto contraste del cumplimiento del principio institucionalista de causalidad acumulativa sobre uno de los componentes de la categoría, las cooperativas, para el caso español en la primera década de 2000. Unas conclusiones finalizan el trabajo.

\section{2.- Razón de ser de una propuesta conceptual alternativa de bases intersecadas, pero no enfrentada}

La respuesta a la pregunta que encabeza el epígrafe tiene que ver con la consideración contemporánea de la Economía Social, y no con cuestionamientos de las bases epistemológicas de la diversidad de sus concepciones ubicadas en distintas geografías; ya que el lenguaje, en ocasiones, termina por convertir en controvertidas cuestiones en las que hay acuerdo. Este trabajo ha procurado la viabilidad de intereses comunes a todas las entidades que completan el conjunto por vías no tratadas 
anteriormente -muy tratada es en la perspectiva jurídica, que incluye a las partes desde la norma- sea debido a dificultades para presentar evidencia empírica basada en su medición, sea debido a la distinta percepción de la concepción genérica en distintas geografías.

No obstante, hay que ser tributario del conocimiento previo, y conviene destacar como referencias cercanas, defensoras de una definición en sentido amplio y que, a la vez, han estimado cifras sobre su peso específico en la economía española, como las aportaciones ${ }^{1}$ de Barea $(1990,1992)$, Chaves (1999), García Delgado (2005, 2009), y Monzón (2006). Pero también el compendio teórico, sin medición, de Sajardo (1996) que hace ya dos décadas ofrecía puntos de encuentro entre las entidades componentes y coincidencias entre las perspectivas europea -Économie Sociale-y anglosajona -Non Profit-, en la explicación del origen de las entidades del segmento No Lucrativo de la Economía Social. El texto bien orienta la posibilidad de integración de unos componentes, a priori, tan heterogéneos.

Buena parte de la explicación de que la literatura sobre el Tercer Sector -y, en suma, la Economía Social como se verá- se centrara en el "porqué son" tiene que ver con autores de raíz ortodoxa que han incorporado la circunstancia institucional en sus concepciones y modelos, avanzando en el conocimiento del funcionamiento de la estructura de la producción (oferta) y del consumo (demanda) que terminan derivando sus orígenes, sea en costes de transacción; la superación de asimetrías informativas (Hansmann), cuando se enfrentan a uno u otro lado del mercado agentes de muy distinto tamaño y poder económico; los fallos de contratos; los fallos del sector público (Weisbrod); los fallos del sector del voluntariado (Salamon); otros fallos como los del sector altruista (Rose-Ackerman); los del sistema de partidos políticos (Downs); o los de las redes primarias de solidaridad (Hayek), entre otras aportaciones que requieren de la teoría de los mercados; cuando, paradójicamente, buena parte de sus componentes -recuérdese al Sector No Lucrativo- carecen estrictamente de ese propósito. A las anteriores cabe añadir la aportación heterodoxa basada en del fallo del sistema global capitalista, de Polanyi, en cierta medida cercana a las conclusiones que se irán obteniendo en las siguientes páginas.

Las referencias académicas mencionadas al principio conforman la concepción genérica y comúnmente admitida sobre Economía Social en España, pero también en el entorno europeo, pues hacen coincidir sus componentes con los principios orientadores en el Artículo 4 de la Ley 5/2011 de Economía Social de España2. Además, los referentes académicos señalados son conscientes de la controversia entre término, significado y componentes, que entroncan con la norma española, y confluyen con la definición expresada en la Carta de la Economía Social de la Conferencia Europea de Cooperativas, Mutualidades, Asociaciones y Fundaciones (CEP-CEMAF) 3 en 2002 antecesora de Social Economy Europe4 y sugerida por la Comisión Científica Nacional e Internacional del CIRIEC. Así, el concepto

1.- Los profesores Barea -desaparecido el 7 de septiembre de 2014-, Chaves y Monzón son exponentes académicos nacionales en este campo, e internacionales, por su larga representación y presencia en España en el Centre International de Recherches et d'Information sur I'Economie Publique, Sociale et Coopérative, CIRIEC, creado en 1947, con sede en la Universidad de Lieja (Bélgica), y que en España tiene su sede en la Universidad de Valencia desde 1986.

2.- $h$ ttp://www.boe.es/boe/dias/2011/03/30/pdfs/BOE-A-2011-5708.pdf

3.- Organismo que sustituye a la Conferencia Europea Permanente de Cooperativas, Mutualidades, Asociaciones y Fundaciones (CEPCMAF), creada en noviembre del 2000, y que proponía, ya en su propio nombre, una concepción amplia del sector.

4.- http://www.socialeconomy.eu.org/spip.php?article263 
sería el integrado por las entidades que cumplen los siguientes principios complementarios, no constitutivos de un conjunto intersección, pero ampliamente asentado:

- Primacía de la persona y del objeto social sobre el capital.

- Adhesión voluntaria y abierta.

- Control democrático por sus miembros.

- Conjunción de los intereses de los miembros y del interés general.

- Defensa y aplicación de los principios de solidaridad y responsabilidad.

- Autonomía de gestión e independencia respecto de los poderes públicos.

- Principio de No Distribución de Beneficios (PNDB) o destino de la mayoría de los excedentes a la consecución de objetivos a favor del desarrollo sostenible, la mejora de los servicios a los miembros y el interés general.

A partir de los anteriores principios, se consigue un conjunto de entidades formado por Asociaciones, Fundaciones, Cooperativas (junto a Sociedades laborales, en el caso español, donde el trabajador es socio capitalista), Mutualidades y Entidades Singulares (Cáritas, Cruz Roja y ONCE, en el caso español, entidades que por su singularidad, merecen considerarse fuera de las bien definidas anteriores $)^{5}$. Su trascendencia comienza a ser persistentemente reflejada en las más importantes instituciones europeas, como el Comité Económico y Social Europeo (Dictamen 01/10/2009 sobre "Diversidad de formas de empresa") y el Parlamento Europeo (Informe sobre Economía Social, 26/01/2009), entre otros informes, ponencias y dictámenes posteriores.

La corriente europea de la Economía Social, como primer grupo de referencias, camina junto a las referencias españolas -no por ser estas diferenciadas, sino porque cierta evidencia a tratar en este trabajo versa sobre España- destacando a Defourny, Fravreau y Laville (1997), Defourny y Develtere (1999) sobre la propuesta de definición en sentido amplio en función de sus entidades efectivas; o las de Borzaga y Defourny (2001) en la preocupación de la inclusión de los emprendimientos sociales, fuertemente vinculados a CIRIEC, influyendo determinantemente en la concepción defendida por la organización científica; y también diversas, no asociadas directamente con la escuela, de Bridge y otros (2009), Hudson (2009) y Uluorta (2009), donde se discute de nuevo la controversia en la definición y las relaciones con la posible solución cooperativa a la reciente recesión por parte de entidades de la Economía Social, que se repite de manera previsora en Noya y Clarence (2007) y anteriormente por Amín, Arash y Hudson (2002) como formas de solucionar problemas socioeconómicos, inclusivos, con un Estado de Bienestar empobrecido.

Un segundo grupo de referencias sobre el señalado sentido amplio se vincularía a las redes de capital social. Concepto que abarca lo lucrativo y no lucrativo concretando alternativas al funcionamiento de entidades tradicionales o "de negocios" compatibles con el espíritu de la Economía Social, 
al vertebrar Economía y Sociedad, y que, según el Banco Mundial ${ }^{6}$ „ «(...) se refiere a las instituciones, relaciones y normas que conforman la calidad y cantidad de las interacciones sociales de una sociedad», " (...) no es sólo la suma de las instituciones que configuran una sociedad, sino que es asimismo la materia que las mantiene juntas». Requiere de imbricaciones entre la sociedad civil y la gobernanza, la participación y el empoderamiento como contrapesos al Estado, en una idea de equilibrar el protagonismo de todo agente económico en el desarrollo socioeconómico, para poder actuar de manera flexible ante las vulnerabilidades de la población.

Las ideas iniciales de capital social, de Putnam (1993) y Coleman $(1988,1990)$, se asociarían a ideas de los grupos de referencias anteriores sobre Economía Social, sobre el papel de la sociedad civil y sus organizaciones, al voluntariado, a entidades que no son plenamente seguidoras de la máxima ganancia pecuniaria personal en beneficio de la cooperación y la inclusión socioeconómica, así como a redes informales de personas y grupos. Por ejemplo, siguiendo la taxonomía de capital social de Siles, Robinson, y Schmid (2003), mostraría redes basadas en sentimientos de respeto y relaciones asimétricas entre personas con pocos intereses comunes (bridging o capital social de aproximación), que se interpretan como afines a las que se encuentra en las asociaciones o fundaciones; o las basadas en sentimientos moderadamente intensos de conexión, como el respeto, la confianza y el compañerismo, así como de personas que realizan tareas parecidas, o que comparten responsabilidades similares en, por ejemplo, sociedades laborales, cooperativas y mutualidades (linking o capital social de vinculación).

Un tercer grupo de referencias se asocia a la Economía Social y Solidaria (ESS, en lo sucesivo); concepto de fuerte impronta en Latinoamérica, funcionalmente importante en la preocupación por el desarrollo local, y con una fuerte tradición de iniciativas de reciprocidad y comunitarias, denominadas "plurales". Se trata de un significante adaptado a las tradiciones y al pensamiento arraigado que caracterizan a la geografía latinoamericana. Esto no quiere decir que Occidente no aplique experiencias de ESS -se reconocen mezclas de circuitos cortos de producción y consumo Ecológico y Finanzas Solidarias, entre otras, muy implicadas con la Economía del Bien Común de Felber (2012)-.

Las aportaciones de la ESS difieren fuertemente de la ortodoxia económica. Destacan, entre otros, Coraggio (1997, 2000 y 2009), Gaiger (1999, 2002, 2004, 2007 y 2008), Singer (2000, 2007), Morais y Bacic (2008 y 2009) y Morais y otros (2010). La última referencia representa el intento más actual, promovido por la OIT7 ${ }^{7}$, en la búsqueda de una definición en sentido amplio que deja fuera, sin embargo,

6.- Que comienza en 1996 una iniciativa para desarrollar un modelo que midiera el capital social con el objetivo de prevenir la pobreza y potenciar el desarrollo, en parte mezcla de las sugerencias de Sen, sobre la ideas originales, con algunas reservas, de Putnam (1993) y Coleman $(1988,1990)$

http://web.worldbank.org/WBSITE/EXTERNAL/TOPICS/EXTSOCIALDEVELOPMENT/EXTTSOCIALCAPITAL/0,,menuPK:401021 pagePK:14 9018 piPK:149093 theSitePK:401015,00.html

7.- A través de la Academia sobre Economía Social y Solidaria http://socialeconomy.itcilo.org/es, especialmente en sus ediciones de 2010 en Turín, y 2011 en Montreal (Canadá), posteriormente en Agadir (Marruecos) en 2013, en Campinas (Brasil) en 2014 y en Sudáfrica en julio de 2015. La sexta edición de la Academia promovida por la OIT, el Instituto Nacional de la Economía Social (México) y la Universidad Iberoamericana Puebla (México), buscan divulgar las prácticas de la Economía Social y Solidaria sobre el terreno. No obstante, no se ha avanzado sobre principios comunes y ni al respecto de las intenciones de la medición de la ESS, para avanzar en su mejor conocimiento. Destaca por la divulgación sobre experiencias locales innovadoras socialmente, exitosas pero aisladas, sin estimaciones de conjunto. 
a entidades que no produzcan bienes y servicios que adquieran otros, y concentrándose en Organizaciones y Emprendimientos Sociales y Solidarios (OESS, en adelante). Por ello, esta propuesta viene a ofrecer una definición sobre las organizaciones y empresas basadas en principios de solidaridad y participación, que producen bienes y servicios (Morais y otros, 2010). Trata los circuitos cortos de producción y consumo (Morais, 2010), así como de iniciativas de empleos verdes, las relacionadas con la conservación del medio ambiente. También acoge la iniciativa de trabajo decente al modo que lo acuña la OIT (Somavia, 1999) ${ }^{8}$, que en algunos casos no es correspondido coherentemente puesto que la ESS admite casos de trabajo informal, para sustento familiar, donde los derechos laborales, la representación y voz de la sociedad civil pasan a un segundo plano. Por ello, es difícil el intento de medición y, así, el avance en el conocimiento del término, ya que bajo ese criterio, por ejemplo, una cooperativa lo será independientemente de que sea formal o informal, en tanto que es «asociación autónoma de personas unidas voluntariamente para satisfacer sus necesidades y aspiraciones económicas, sociales y culturales en común a través de una empresa de propiedad conjunta, y de gestión democrática», concepción aprobada por la Alianza Cooperativa Internacional en su Congreso de Manchester (1995) ${ }^{9}$, y por la OIT en 2002, en la Recomendación $193^{10}$. En definitiva, se consideraría como un subconjunto ampliado de la Economía Social occidental, ya que habría entidades formales -es decir, fiscalizadas; evítese confundir el término con la institución efectiva que se verá en el siguiente apartado- que no pertenecerían estrictamente a la categoría, a la vez de que se incluiría un conjunto de entidades informales -no fiscalizadas- de profundo calado humano, como las asociadas a la subsistencia familiar.

Un cuarto grupo de referencias, con algunas décadas más de tradición, trata propuestas no unidas, bajo la idea de que las organizaciones pueden obtener una rentabilidad social con una previa rentabilidad pecuniaria personalista, no siendo esa prioridad su razón de ser, ni, por tanto, una componente "constitutiva", sino secundaria, de la Economía Social en sentido estricto. Confluyen paralelismos y similitudes a la concepción de empresa social de la Red EMES (Defourny y Nyssens, 2012), algo más sistematizados en la actualidad por Sánchez y Pérez (2015), que estudian la atención legal reciente a este no tan nuevo modelo emprendimiento en España, que distingue empresa social de emprendimiento social, incluso finas fronteras con la Responsabilidad Social Corporativa como parte del constructo -y sobre la el que escribe ofrece una no razón de inclusión en la categoría de Economía Social, como componente constitutivo de ella, sino como institución indirecta-. También, Pérez y Sánchez (2015) reconocen problemas de financiación de la empresa social, y la necesidad de fomentar culturalmente, a través del Sistema Educativo, al emprendedor social. En todo caso, la controversia sobre la razón de inclusión o no de ciertas instituciones en la categoría no difiere de la borrosidad de las fronteras entre conceptos próximos, cuestión ya advertida por Monzón (2006) y recurrente en la discusión conceptual del término.

8.- $h$ ttp://www.ilo.org/public/spanish/standards/relm/ilc/ilc87/rep-i.htm) para establecer las características que debe reunir una relación laboral y considerar que cumple los estándares laborales internacionales, de manera que el trabajo se realice en condiciones de libertad, igualdad, seguridad y dignidad humana.

9. $h$ ttp://2012.coop/en/what-co-op/co-operative-identity-values-principles

10.- http://www.ilo.org/dyn/normlex/es/f?p=1000:12100:0::NO::P12100_INSTRUMENT_ID:312531 
La premisa básica de este conjunto de referencias consiste en que la obtención de beneficios (personalistas o colectivos) no es necesariamente incompatible con instituciones sin fines de lucro o que incorporen voluntariado. Constituiría las iniciativas productivas sostenibles ambiental y socialmente; no quedando tan claro que deba incluirse la posterior reparación (o construcción) de capital social en la sociedad previa destrucción (u omisión) por entidades que unen el lucro pecuniario de finalidad personalista y la actividad no sostenible económica, ambiental y social paralelamente a su compensación posterior. Una paradoja que genera cierta suerte de capital social, aunque se desconoce si es netamente positivo. Son ejemplos:

- las organizaciones que contempla la Economía del Bien Común [Felber (2012)].

- el emprendedor social, sea en iniciativas nacionales [de la CSEF canadiense (http://www.csef.ca/)] o internacionalmente, como la Iniciativa de la Empresa Social de la Comisión Europea (http://ec.europa.eu/internal_market/social_business/) y del Programa de Desarrollo de la Economía Local y el Empleo (LEED) de la OCDE (http://www.oecd.org/cfe/leed/social-economy.htm). Las dos últimas fuertemente ligadas el desarrollo territorial, basadas en entidades con ánimo de lucro colectivo como de finalidad individualista con tintes de sostenibilidad social y medioambiental. Propuestas que añaden valor social, pero obtienen sus recursos fuera de la esencia constitutiva de la Economía Social, y que han podido restar con anterioridad aquel valor social, compensando más que añadiendo.

- la reciente propuesta del emprendimiento humano, del Consejo Internacional para la Pequeña Empresa (http://www.icsb.org/), que pretende indagar en el cambio de peso de los factores de corte más humano y menos rentable pecuniariamente en los emprendimientos, preocupándose sobre ética, ecología, igualdad, empoderamiento de los trabajadores en la organización y su servicio a la sociedad.

Los cuatro grupos anteriores, que ofrecen principios próximos entre sí, pero alternativos a los de las organizaciones tradicionales societarias, no tienen una necesidad primordial de encontrar elementos comunes. En todo caso, este trabajo remarca la llamada de atención de Defourny (1992), hace casi 25 años, sobre identificar lo más claramente posible lo que fundamentalmente distingue a las entidades de la Economía Social de otras entidades, ante la dificultad de reconocer una teoría general de la Economía Social, debido a la diversidad jurídica, de lenguas (significantes y significados) y de contextos socioculturales. Pero, se insiste, estas diversidades fluyen paralelas a intenciones de aproximarse como conjunto alternativo a algo: eso es una extensión de la agregación de la ontología del lenguaje de Echeverría (2008); lenguaje que dinamiza y transforma lo que observa el ser humano. Si el lenguaje "utilizado" es el mismo, podrá explicarse de manera similar el comportamiento del hombre y de las organizaciones humanas que observa. Concluir la problemática mediante posturas reduccionistas sobre la imposibilidad de un "común general" por acuñarse como idealismo o no factible, muestra una falta de valor intelectual y una contradicción ante la evidencia del hecho de que tales grupos de propuestas que se encuentran, y no sólo se acercan, en foros de debate, desde locales a internacionales. Con lo cual, disponen de elementos comunes. 
Entonces, ¿qué dificulta entroncar una categoría común sobre Economía Social -no asociada a la cuestión jurídica-? Conscientes de la complejidad y el espacio necesario para tal discusión, se señala una evidencia centrada en su impronta académica. En efecto, las revisiones bibliográficas sobre el término más abarcador, el de Economía Social no son tan atractivas académicamente como las que, supuestamente, componen la categoría (altruismo, filantropía, cooperativismo, mutualismo, inclusión social o solidaridad económica). La base de datos bibliográfica SCOPUS ${ }^{11}$ (Cuadro 1), observa cierta expulsión en el avance del conocimiento y la definición de la Economía Social en beneficio de sus componentes, lo cual es fruto de la lógica de la especialización en la investigación científica, y de la máxima de acotar sus objetos de estudio, al estar generalmente admitido su ámbito genérico; así pues, tiende a obviarse -no a olvidarse- bien por el recelo de no ser empirista, formalmente hueco, o bien debido a la necesidad de publicar trabajos con impacto académico, cargados de metodologías cuantitativas de corte individualista, simulando a las de ciencias experimentales asentadas, pero que carecen, en muchos casos, de explicación conectada con la razón de ser social. Así, se obtienen resultados bien confusos, bien obvios o iguales al contrastarse los mismos hechos con métodos más sencillos, adecuados al objeto de estudio (el grupo, no el individuo), y de similar fiabilidad.

Por tanto, si la realidad de la entidad social es el grupo de individualidades, entonces la finalidad colectiva del lucro, la gratuidad de bienes, servicios y factores o un precio no significativo de ellos anula la propuesta de lucro de finalidad individual y, por tanto, la del análisis de la entidad como individualidad, pero no como grupo o red. No obstante, la opción mayoritaria en Ciencia Económica destaca el contraste desde el individualismo metodológico, teórico y aplicado, sobre concepciones (muy) previas. En consecuencia, no aparecen, por falta de fomento y orientación, el número de propuestas de normas y políticas públicas deseado por la sociedad, que reduzcan el riesgo de fragmentación y polarización social, y que protegerían a buena parte de grupos, sociedades y geografías en riesgo de exclusión, económica o social.

SCOPUS, entre 1974 y 2012, asocia a un ámbito amplio de la Economía, entre 2,7 y 3 millones de referencias entre artículos, conferencias, notas de investigación, comunicaciones, etc. Como alrededor de $3 / 4$ partes de las referencias está en inglés, además de que referencias en otros idiomas tienen la traducción de título, palabras clave y resumen, las búsquedas se han realizado en lengua inglesa, sin perder representatividad los resultados, se realizaron consultas para obtener los filtros resultantes las entidades componentes, el conjunto, y los valores representativos de la Economía Social: "voluntary associations" y "ngo", "foundation", "cooperative" y "labor society", "mutuality" y "social inclusión centre"/"social inclusión entity", "altruism", "philanthropy", "cooperativism", "mutualism" y "solidarity". Seguidamente, al incluir en las consultas la condición "AND", las intersecciones totales no ofrecían resultados, y al considerar el término conjunto "social economy", "third sector" el número de referencias se reduce enormemente. El resultado es una ínfima representación en la muestra total de

11.- http://www.scopus.com/home.url. Dispone de alrededor de 53 millones de registros desde 1823, unos 42 millones entre 1974 y 2012. Va acumulando referencias, 10 cual no significa que el año fechado sea el año cerrado para los datos disponibles, pero sí más completo, y que un año tan reciente como 2014 se considere un año incompleto al incorporar referencias a una velocidad diferente a la de años anteriores. 
referencias académicas de Economía. No obstante, sus valores componentes, así como la consideración de sus entidades por separado llegan al 0,3 y al 1,8 por 100 de las referencias sobre Economía en los últimos 40 años, una vez que se suman (Cuadro 1). Estos indicadores dan cuenta de su reducida repercusión e impacto académico, aunque creciente. y son resultados que cotejan el déficit del tratamiento de ciertos valores humanos (y económicos) bien considerados por la sociedad en estudios sobre hechos e ideas económicos/as.

\section{Cuadro 1. Referencias asociadas a la Economía Social en la muestra de SCOPUS entre 1974 y 2012 en las materias del ámbito de la Economía}

\begin{tabular}{|l|ccc|c|}
\hline & $\begin{array}{c}\text { Ciencias } \\
\text { Sociales (a) }\end{array}$ & $\begin{array}{c}\text { Administración de } \\
\text { empresas y } \\
\text { contabilidad (b) }\end{array}$ & $\begin{array}{c}\text { Economía } \\
\text { Econometría } \\
\text { y Finanzas (c) }\end{array}$ & $\begin{array}{c}\text { Total } \\
(\mathrm{a}+\mathrm{b}+\mathrm{c})\end{array}$ \\
\hline Altruismo (1) & 1.932 & 370 & 861 & 3.163 \\
Filantropía (2) & 724 & 291 & 167 & 1.182 \\
Cooperativismo (3) & 31 & 9 & 6 & 46 \\
Mutualismo (4) & 454 & 112 & 39 & 605 \\
Inclusión Social (5) & 1.352 & 152 & 109 & 1.613 \\
Empatía (6) & 3.348 & 454 & 159 & 3.961 \\
\hline Valores (suma vertical 1 a 6) & 7.841 & 1.388 & 1.341 & 10.570 \\
\hline Asociaciones Voluntarias y ONG (7) & 2.451 & 301 & 313 & 3.065 \\
Fundaciones (8) & 24.065 & 7.629 & 3.843 & 35.537 \\
Cooperativas (9) & 13.847 & 3.869 & 3.578 & 21.294 \\
Mutualidades (10) & 77 & 18 & 11 & 106 \\
Entidades de inclusión social (11) & 2 & 1 & 1 & 4 \\
Empatía y Economía (12) & 13 & 6 & 3 & 22 \\
\hline Entidades (suma vertical 7 a 12) & 40.455 & 11.824 & 7.749 & 60.028 \\
\hline Economía Social (13) & 283 & 79 & 134 & 496 \\
Tercer Sector (14) & 574 & 95 & 68 & 737 \\
Economía Solidaria (15) & 28 & 1 & 7 & 36 \\
Empatía y Economía (16) & 13 & 6 & 3 & 22 \\
Economía Social / Tercer Sector (17) & 27 & 6 & 4 & 37 \\
\hline Total ámbito de la Economía & 2.296 .679 & 416.864 & 654.961 & 3.368 .504 \\
\hline
\end{tabular}

FUENTES: Elaboración propia sobre SCOPUS, http://www.scopus.com.

En consecuencia, el empirismo científico no ayuda a aunar una definición basada en principios comunes -sí complementarios-. Por ejemplo, la investigación del altruismo o la filantropía, que considera como unidad de análisis a la persona o a la fundación individualmente, aísla la condición de análisis necesaria: las relaciones interpersonales y la importancia del fundamento del bien o servicio producido y con- 
sumido, que no es otra cosa que un bien o servicio relacional (CIIAC, 2003). Es entonces cuando se separa la consideración de los grupos de individuos en el estudio: en el primer caso, asociados o voluntarios de las asociaciones u ONG; en el segundo caso, el grupo de voluntarios o de asistentes de investigaciones auspiciadas. Y sucede lo mismo para el estudio del segmento cooperativismo-mutualista y el de las entidades de inclusión social. Por tanto, el paso del análisis individual-y su método de contraste sobre la evidencia empírica- al de las relaciones interpersonales -entre grupos y entre individuos y grupos- hace necesario tener en cuenta una finalidad prioritaria para tales entidades formales: el no ánimo de lucro personalista, de cierto beneficio colectivo; justificado por la confianza mutua, la apuesta por emprendimientos sostenibles -económica, social y medioambientalmente, Comisión Brundtland, 1987-, o por la inclusión de colectivos en riesgo de exclusión socioeconómica. Lo anterior lleva asociada la sustitución del individualismo metodológico, menos intuitivo, por métodos que derivan del análisis de redes, pues aquellos no se ocupan de la variable relacional, concepto básico en la preocupación del estudio teórico y aplicado de los grupos de individuos en la Economía Social.

Así las cosas, la dificultad de integrar un concepto en sentido amplio, debido a la percepción académica del término, se resumiría en dos aspectos. El primero considera cierta fragmentación entre los valores componentes del conjunto y el concepto en sentido amplio. El segundo tiene que ver con la controversia relacionada con la comprensión de las unidades de estudio y sus valores humanos inherentes -altruismo, filantropía, mutualismo, inclusión de personas o grupos de ellas, entre otros valores- para sostener una concepción extensa y común a tales representaciones. Esto requiere de la red de relaciones entre unidades objeto de estudio, mayoritariamente interpersonales, y no a un individuo aislado del resto, que deriva del empirismo individualista. No obstante, se aceptaría aquí un proceso de adaptación metodológica, diferencial y no mimética, de los métodos aplicados desde las ciencias experimentales, o de la economía convencional, a la investigación sobre Economía Social, por los requerimientos de una carrera académica, consecuente con el impacto académico de las corrientes convencionales aplicadas y teóricas.

Además, la carencia de un "lenguaje común" transforma en controvertidas concepciones que geográficamente tienen significantes diferenciados para similares puntos de encuentro. La razón de ello -mejor, la sinrazón- tiene que ver también con cierta mezcla de prejuicios, tradiciones y pensamiento dominante que encierra el tratamiento de lo individual y lo colectivo en diversos ámbitos geográficos, que mezclan concepciones incompatibles en el fondo. Por ejemplo, la incorporación de la informalidad en el concepto de Economía Social iberoamericano frente al occidental, la inclusión de la cooperativa de gran tamaño, o las empresas unipersonales lucrativas, entre otras. ¿Tiene sentido construir una concepción conciliadora que se ajuste a unos signos suficientes que convergen? En efecto, parece que la complejidad de la realidad social no puede ser el pretexto de la no conciliación si la discusión de ideas es el motor del pensamiento. En cualquier caso, la propuesta debe buscar, como mínimo, un acercamiento como base del conocimiento sucesivo. El leitmotiv del estudioso no puede detenerse en la dificultad de una definición, ni de una medición secundaria, si la academia intenta incentivar una definición basada en principios-valores cercanos, y un método de medida, que es ya conocido en el plano macroeconómico y para los componentes de la Economía Social, con el objeto de realizar comparaciones en el tiempo y en el espacio. 
Tampoco ayuda la limitada disponibilidad de información ni, por tanto, de estimaciones cuantitativas sobre la categoría en términos de detalle -desagregación-y serie temporal. Sobre todo, para finalidades de comparación internacional o de evaluación de políticas sobre su fomento, lo cual es otra prueba de la necesidad de una definición mínima. Todo ello obliga al estudioso del tema a realizar estudios parciales que requieren un coste elevado al no aprovechar el conocimiento que se acumularía si hubiera una mayor continuidad y unos principios troncales. Aún España, que resulta ser el país de iniciativa más notable en el tratamiento de las experiencias de cuantificación en sentido amplio sobre la Economía Social, adolece de esta carencia. En efecto, la Ley 5/2011, en su disposición adicional $5^{\text {a }}$, insta a observar los efectos y consecuencias de la Ley a los dos años de su entrada en vigor, pero no hay publicidad de algo parecido después del 30 de abril de 2013. Para ello podrían haberse continuado los criterios formales -los del Comité Científico de CIRIEC-aceptados en la Ley, admitidos en los tres estudios abarcadores sobre el sector promovidos por la Fundación ONCE: FONCE-2001 y FONCE-2005, por el equipo dirigido por el García Delgado (2005,2009), y el dirigido por Monzón (2010) y fechado en 2008.

Lo anterior no obvia la existencia de cuantificaciones internacionales, parciales en todo caso, pues existe cierta riqueza de estimaciones e investigaciones de componentes puntuales -sobre el cooperativismo 0 el sector voluntario, así como tratamientos del altruismo, la filantropía, sobre todo-, pero sin la posibilidad de realizar contrastes relacionados con la densidad de sus componentes sobre un total, al ser necesario hacer coincidir en el conjunto de datos a trabajar, al menos, una de tres dimensiones: espacio -países- , tiempo -fechado de las cifras- y tipología de entidades. Así, las estimaciones de Cuentas Satélites de las Cooperativas se concentran en Europa, y no agrupan a más de seis países, siendo los más frecuentes y extendidos los para España y Portugal. La propuesta portuguesa, también dentro de un proyecto más abarcador, se presenta en primavera de 2013 , fruto del protocolo de cooperación de 2011 entre el Instituto Nacional de Estadística portugués y la Cooperativa António Sérgio para la Economia Social, CIPRL (CASES): las Cuentas Satélite de la Economía Social para Portugal en 2010 (http://www.cases.pt/atividades/contasatelitees), que dispone de estimaciones de voluntariado para 2012. Incluye, como los trabajos fechados para 2001 y 2005 en España, la cuenta consolidada del conjunto de entidades componentes de la Economía Social y, por tanto, las correspondientes al cooperativismo.

Junto a las anteriores experiencias española y portuguesa, existen otros cuatro proyectos europeos sobre Cuentas Satélite de las Cooperativas y las Mutuas en 2011 (http://ec.europa.eu/enterprise/policies/sme/files/cooperatives/satellite_accounts_for_coops_and_mutuals_final_report_en.pdf) fechados con un desfase de ente uno y cuatro años, para Bélgica (fechado en 2007), Bulgaria (fechado en 2010), Serbia (fechado en 2009) y la antigua República Yugoslava de Macedonia (fechadas para 2002 y 2008, y avances para 2010), mostrados por Monzón y Chaves a fines de 2012 a petición del (CESE) sobre la Economía Social en Europa (http://cde.uv.es/documents/menudocuintern/item/9834la-econom\%C3\%ADa-social-en-la-uni\%C3\%B3n-europea.html). 
También conviene mencionar dos proyectos incipientes que compensan las limitaciones de disponibilidad de fuentes estadísticas sobre la Economía Social en Latinoamérica, en general, y del cooperativismo, en particular. La primera, aún no materializada, se madura en la Ciudad de México entre los días 4 a 6 de diciembre de 2013, en un Foro Internacional sobre "La estrategia productiva en el desarrollo social", organizado por la Secretaría de Desarrollo Social (SEDESOL) del Gobierno mexicano con CIRIEC-España, al respecto a la elaboración de un Libro Blanco de la Economía Social y Solidaria mexicana, y de sus Cuentas Satélites. La segunda, materializada en la estimación de las Cuentas Satélites del Cooperativismo Colombiano ${ }^{12}$ dentro del proyecto "Impacto Social y Económico del cooperativismo en Colombia" auspiciado por el Centro de Investigación del Cooperativismo (CENICOOP, http://www.cenicoop.coop/investigaciones-y-estudios/en-curso), que se concreta en un documento metodológico (Alarcón, Castro y Rodríguez, ca. 2016) y el Informe Final (Alarcón, ca. 2016), cerrados en abril y junio de 2013, respectivamente. Los indicadores colombianos estimados se disponen para la serie 2003-2010, e incluye ejercicios sobre contabilidad del crecimiento cooperativo comparado al de la economía nacional, construcción de Tablas Input Output y análisis comparado de redes de relaciones intersectoriales cooperativas respecto a la economía colombiana.

El resto de países europeos acatan las recomendaciones de la UE en el avance del diseño y publicación de estadísticas de la Economía Social, pero ninguno ofrece en la estadística oficial unas cuentas satélites de la Economía Social, en las que sólo Bélgica, Hungría, Polonia y la República Checa muestran una intención de publicar una estadística diferencial del sector no lucrativo. Hungría se interesa por los ingresos y donaciones; Polonia por el empleo, el tamaño de entidades y el voluntariado; y la República Checa por el empleo, el voluntariado y las horas de donaciones de tiempo. Sólo Bélgica sigue el Manual de la ONU sobre Entidades No Lucrativas en el Sistema de Cuentas Nacionales 1993 (Naciones Unidas, 2003), y ofrece Cuentas Satélites: descomposiciones del Valor Añadido Bruto, Producción Agregada, sucesiones de las cuentas desde el origen de la producción hasta la capacidad o necesidad de financiación, y empleo, entre otras rúbricas de Cuentas Nacionales. Es un buen ejemplo para Europa, para la que sería oportuno integrar la aplicación del anterior manual para el segmento No Lucrativo y unirlo a la aplicación del Manual para la elaboración de las cuentas satélite de las empresas de la Economía social: cooperativas y mutuas (Barea y Monzón, 2006).

Finalmente, pueden añadirse los ejercicios de clasificación de tipos de organizaciones en función de ciertos ámbitos, que ofrecen intersecciones según varios criterios, acercándose al qué es la Economía Social como los de Pearce (2003) y de Pérez de Mendiguren y otros (2009), así como otros de corte más teórico y con cierta evidencia empírica, como los de Viaña (2008) y Alarcón (2011), que han servido como puntos de inicio de la propuesta de este trabajo. A los que se unen los persistentes escritos que proponen hacer más visible al sector dentro de una acotación lo más consensuada posible, como los de Chaves, Monzón, Pérez de Uralde y Radrigán (2013) y el de Fajardo (ca. 2016). El primero, un acertadísimo intento de búsqueda de criterios conceptuales comunes como base para

12.- Aunque la metodología de ese proyecto puede aplicarse a cooperativas, fondos y mutuales en Colombia, sólo se implementa para las cooperativas. 
una cuantificación rigurosa de las categorías que pretenden ser comparadas tanto entre países como con respecto a las categorías generales -y agregadas- más significativas y estandarizadas en el plano económico. El trabajo destaca que no debe obviarse el reconocimiento institucional como condición necesaria para poder conceptualizar y comenzar a medir las magnitudes más significativas y comparables a las referencias más estandarizadas, para proponer otras referencias propias y diferenciadoras. El segundo, fuertemente relacionado con el objetivo de este artículo y desde una perspectiva jurídica, plantea la ya mencionada "dificultad de definición" de Defourny (1992) y se considera un buen complemento a este trabajo para la discusión sobre una propuesta integradora. En efecto, puesto que ambos trabajos pretenden la coherencia de lo que plantea el Catálogo de Entidades que propone la Ley 5/2011: clasificar qué es y qué no es Economía Social en tanto en cuanto entidades componentes de la categoría, y que no son otra cosa que instituciones formales desde la propuesta institucionalista contemporánea, como pasa a desarrollarse a continuación.

\section{3.- Una propuesta conceptual de la economía social desde el institucionalismo económico y evolutivo contemporáneo}

Aunque el tratamiento de las instituciones es variado y sus raíces en el pensamiento económico son profundas (Rutherford, 1994), desde la Economía Clásica, por establecer un comienzo, el programa Marxista y el Historicismo Alemán, así como la Escuela Económica Austríaca, estudian la institución. Y, como si se tratara de una regla mnemotécnica, se preocupan por las instituciones los institucionalistas; y así, tanto los autores del "viejo" Institucionalismo Económico Originario Americano (IEO, en lo sucesivo) como los del "nuevo" o contemporáneo Institucionalismo, del que se detectan, siguiendo a Grandlgruber $(2007,2010)$, tres propuestas: la Nueva Economía Institucional (NEI, en lo sucesivo), la Economía Evolutiva (EE, en adelante) y el Nuevo Institucionalismo Económico (NIEC, para las siguientes referencias al término). Todo ello, conscientes de que la NEI introduce a las instituciones en el análisis económico ortodoxo después de admitir el error de no contemplar el entorno institucional en la asignación de los recursos por el mercado (Coase, 1992) ${ }^{13}$, posteriormente a considerar como "empirista" o "no teórico" al "viejo" Institucionalismo por haberlo incluido (Williamson,1994).

El Nuevo Institucionalismo Económico (NIEC) es una de las tres corrientes de la Economía Institucional Contemporánea, cuyo exponente actual es Geoffrey Hodgson ${ }^{14}$. La propuesta mantiene

13.- Ronald Coase, premio Nobel en 1991, señaló en su discurso de agradecimiento que su principal contribución a la teoría económica fue « (...) mostrar la importancia de lo que se podría llamar la estructura institucional de la producción para el funcionamiento del sistema económico".

14.- http://www.geoffrey-hodgson.info/. Profesor en la Universidad de Hertfordshire, donde dirige el "Centre for Research in Institutional Economics", revisando a T.B. Veblen en la preocupación de la tradición del IEO. 
una continuidad acorde con las aportaciones principales del Institucionalismo Económico Original15 pero no se reduce a ellas (Grandlgruber, 2007, 2010).

Para Veblen (Hodgson, 2001), las instituciones son hábitos de pensamiento establecidos, comunes a la generalidad de los hombres. Las considera fenómenos cambiantes que ayudan a seleccionar individuos más aptos a través de la adaptación de las instituciones a los hábitos del entorno (Veblen, 1994). Como el resto de los economistas institucionales, entiende por institución formal cualquier organismo o grupo social que, con unos determinados medios, persigue la realización de unos fines o propósitos. Por ejemplo, leyes y organizaciones lo son, y se diferencia de la institución informal en el grado de concreción efectiva o práctica, siento ésta algo más genérico: la forma en que se relacionan los seres humanos de una sociedad o un colectivo, buscando el mayor beneficio para el grupo, y no necesariamente para todos y cada uno de los individuos componentes de una manera aislada.

Así, las instituciones, serían los usos, hábitos, reglas, rutinas, costumbres o normas por los que se rigen las relaciones sociales y económicas entre los miembros de un grupo. Tales categorías pueden constituirse evolutivamente en instituciones formales; entendiéndose informal el atributo asociado a la institución no explícita, siendo formal, principalmente, la organización o entidad, aunque también las normas garantes de derechos individuales, entre otras categorías. Las ideas sobre el desarrollo del capitalismo como un sistema complejo de Potts (2000 y 2001) y Nooteboom (2000, 2002 y 2003), aplicadas a las relaciones de individuos en instituciones, sean éstas formales o no, iluminan hipótesis que van a ayudar a definir qué es una institución y a explicar su configuración en organizaciones. Por tanto, son ideas válidas para analizar las instituciones formales de la Economía Social y su concepción conjunta. Este es el aspecto que entronca con la introducción del concepto de red y, por tanto, con las posibilidades del Análisis de Redes Sociales como instrumento metodológico para el estudio teórico y aplicado de la Economía Social.

Además, asumiendo que la acción humana impregna de hábitos a las instituciones formales de una sociedad y momento dado (Hodgson, 1993, 2001, 2002), y que éstas se gestan sobre patrones históricos adaptados al entorno específico (ya que, si existen, han pervivido largos procesos de aparición, diversificación y selección), entonces el agente económico institucional toma el relevo del agente económico racional, debido a la evidencia aplicada sobre la racionalidad limitada del individuo, que se ayuda de las instituciones (persistencia de los hábitos, reglas, ...) en los procesos de decisión para conseguir fines, evitando los supuestos ortodoxos de individuos idénticos ${ }^{16}$.

15.- El Institucionalismo americano, de fuerte influencia en el período de entreguerras, cuyos representantes fueron Thornstein Veblen, Wesley Mitchell y John R. Commons. Economistas como Simon Kuznets y John K. Galbraith individualmente continúan el pensamiento institucional. En Europa, G. Myrdal, K. Polanyi, A. Lowe, M. Olson y W. Kapp Todos ellos contrapuestos a las teorías marginalistas y neoclásicas.

16.- También en Mises (1980, ed. 1986, p. 273), razonado sobre bases biológicas. Podrían considerarse pensadores enfrentados, siempre que se encasille en escuelas algo tan diverso como el pensamiento, en vez de las concepciones. 
En consecuencia, se propone, P1, que las entidades de la Economía Social son instituciones formadas por redes de individuos, que se constituyen por una tipología de relaciones entre ellos, basadas en un núcleo común de empatía y/o solidaridad, que son acciones humanas realizadas para la consecución de sus fines. En tanto redes, pueden formalizarse en grafos. Para su demostración, la proposición requiere los axiomas A1, A2 y A3, las definiciones D1, D2 y D3, y los supuestos S1 a S4.

D1. Un grafo $G$ (Gráfico 1) es un par ordenado $G=(V, E)$, donde $V$ es un conjunto de vértices 0 nodos, y $E$ es un conjunto de arcos o aristas, que relacionan estos nodos. El grafo es dirigido cuando hay aristas que tienen un origen y un destino. Así, las relaciones entre individuos de un grupo, sin necesidad de incluir variables cualitativas -atributos-, o cuantitativas, se representarían por un conjunto de lazos (aristas, nexos) entre las unidades (nodos, vértices) del grupo, como también "desde" y "a" él; de forma que son redes que podrán formalizarse en grafos ${ }^{17}$, representantes de relaciones entre individuos que actúan con y en entidades componentes de la Economía Social.

\section{Gráfico 1. Grafo de 5 nodos y 7 aristas}

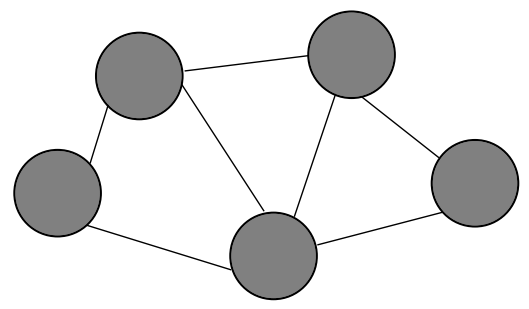

A1. El lenguaje es una institución, en tanto regularidad del hábito de la comunicación humana, y la semántica una regla del mismo. En consecuencia, se trata de una institución necesaria para los procesos de aprendizaje y del avance en el conocimiento. Por tanto, para construir los razonamientos sobre qué son las instituciones.

Los significantes asociados a la Economía Social: altruismo, asociacionismo, asociación, cooperativa, cooperativismo, filantropía, fundación, mutualismo, mutualidad, e inclusión social o socio-laboral, según la Real Academia Española, confluyen en otros dos términos que los engloban: empatía, en el plano cognitivo, como una capacidad humana no explícita, un hábito; y solidaridad, como significado práctico, efectivo, del término anterior, una rutina, y comúnmente utilizado en la geografía latinoamericana como significante genérico de la Economía Social. 
Si las palabras "alguien", "auxilio", "ajeno", "a costa del propio", "compartir", "mutuo", "otro", "otros", "persona", se refieren obviamente al individuo en relación con otro u otros semejantes, sería inevitable una asociación de ideas sobre una categoría colectiva, que sería difícil de segregar individualmente. Así, los dos anteriores significantes, empatía y solidaridad, vendrían a representar regularidades de la acción humana, hábitos genéricos de comportamiento no egoísta, que se particularizan en los valores persistentes y característicos de las entidades que componen la Economía Social. Tales regularidades se muestran en su evidencia formal para el caso español en López (2005), mientras que Novak (2011) trata la evolutiva de la cooperación, la reciprocidad y altruismo.

A2. El comportamiento del individuo se caracteriza por regularidades, como hábitos, reglas y rutinas (para conjuntos de individuos), que pueden ser explícitas -organizaciones o normas- 0 abstractas-valores en el campo cognitivo-.

Se asumen tres supuestos. S1, las entidades de la Economía Social se pueden formalizar en grafos, asumiendo que las aristas son los medios o relaciones con los que los individuos, que son los nodos, actúan para la consecución de ciertas finalidades. S2, los medios o relaciones entre individuos son la formalización inicial de hábitos, reglas o rutinas, es decir, de instituciones teóricas y abstractas. S3, la dinámica evolutiva de las instituciones teóricas abstractas es la causa de las instituciones formales $u$ organizaciones.

Así, se puede definir, D2, a las organizaciones, como instituciones formales y grupos de individuos constituidas por cierta relación definida entre ellos, así como por relaciones entre organizaciones, o entre éstas con otros individuos. Se hacen efectivas a partir de hábitos individuales, que vienen a constituirse en rutinas. Por ejemplo, la Alianza Cooperativa Internacional se constituye por la regularidad o persistencia de la asociación de (y por) la práctica cooperativa en la iniciativa empresarial hace casi tres siglos -1844 se toma como el año admitido de la fundación formal de la primera cooperativa, por 27 hombres y 1 mujer, en el poblado de Rochadle, Inglaterra-.

A3. La constitución de una organización se formaliza a partir de hábitos y valores individuales y reglas, pero no garantizan su pervivencia. En efecto, la garantía formal de instituciones se produce conforme a las normas legales vigentes en una sociedad. Una persona jurídica puede constituirse legalmente a la vez que puede no ser fiel a los valores que se plasman en sus principios constitutivos ni en la normativa vigente promulgada que les afecte. En consecuencia, esta condición supone un contrasentido de su ser que la llevará tendencialmente a su extinción -la evidencia señala, sobre todo, a la solución de estos conflictos por la vía judicial-.

El devenir de las organizaciones en general, y de las de la Economía Social en particular, será el resultado necesario de las acciones de los individuos, basadas en hábitos -o en el cumplimiento de ciertas reglas-. Sin normas y ni relaciones afines, es decir, sin medio, no habrá conectividad entre los individuos de una institución formal ni, por tanto, finalidad individual ni colectiva del grupo, teniendo en cuenta, estrictamente, A1, A2, A3, y S2. Por su parte, asumir el S3 es realista en el sentido de que 
existen contrastes evolutivos sobre diferentes mecanismos de la cooperación, cuyo compendio y bibliografía extensa se ofrece en Novak (2011).

Ahora bien, para concretar las relaciones entre, en y con grupos de individuos se presenta una tercera definición, D3, por la que un clique es un subconjunto de una red en el cual los actores están más cercana y fuertemente conectados mutuamente que lo están respecto al resto de los integrantes de la red. Por ejemplo, en relaciones de amistad, enlaces por raza, edad..., es usual que se formen cliques.

Finalmente se asume S4, por el que la empatía y la solidaridad son representantes de relaciones o medios y, por tanto, representables como aristas o nexos entre los individuos que pertenecen a una red.

En consecuencia, es posible la representación formal de los grafos ${ }^{18}$ de las cinco entidades u organizaciones instituciones formales representativas de la Economía Social (Gráfico 2), en tanto existe una demostración de la proposición P1. Las aristas azules son representativas de empatía o solidaridad entre individuos, considerando los contornos y trazos en negro como explicativas de relaciones distintas de aquéllas o de relaciones exógenas. Ahora bien, deben tenerse en cuenta tales relaciones o lazos (aristas) como principios institucionales prioritarios sobre otros, de corte institucional o no, que han sido garantizados o comprometidos por normas constitutivas de la institución formal representada: la organización. Tal taxonomía es susceptible de extenderse a entidades similares en otras geografías diferentes a la española, pues la concreción inicial sólo buscaba el entorno más cercano del que escribe.

\section{Gráfico 2. Mecanismo de cooperación general de la Economía Social}
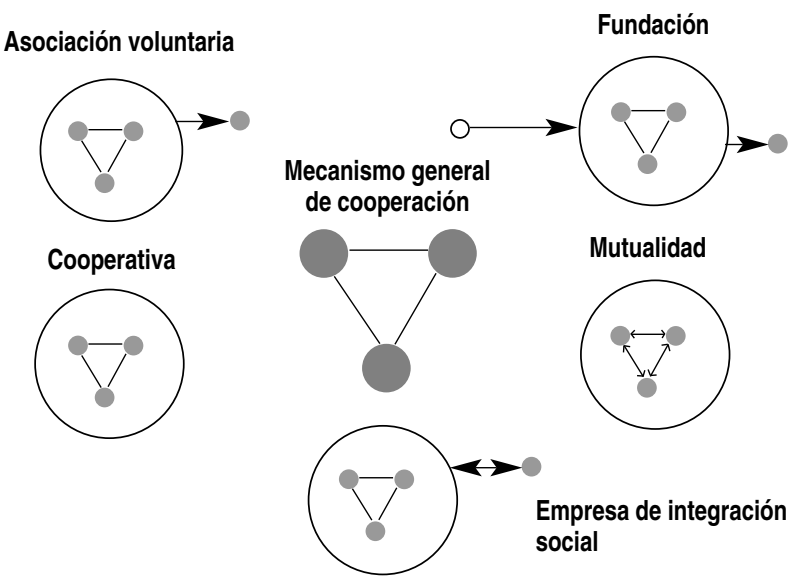

FUENTE: Elaboración propia.

18.- Formalmente, dos nodos unidos por una arista, graficados o no por su dirección, representan ya una relación biunívoca, aunque no se precise. Para la formalización que se plantea aquí, la diferencia de que en los extremos de la arista aparezca la dirección o no vendría a diferenciar la concreción del grafo dirigido de la condición "o" (de un nodo a otro o viceversa) en la relación que se quiere plantear entre los nodos implicados. 
Lo anterior abre la posibilidad de avance de un lema, L1, tal que existe una intersección entre los grafos que representan a las entidades de la Economía Social o Tercer Sector basado en un clique de relaciones de empatía o solidaridad como cociente común entre ellas. En consecuencia, es posible la definición en sentido amplio de ese cociente común del conjunto.

La demostración considera la intersección de los grafos representados en Gráfico 2, que representan las entidades componentes de la Economía Social en sentido amplio bajo el supuesto S4, al conjeturar un núcleo común de los cinco. Esta intersección ayuda, sintéticamente, a ofrecer "a priori" una definición de Economía Social en su sentido más abarcador al ser, la intersección, resultado del común denominador de las relaciones de empatía o solidaridad entre individuos que caracterizan a estas entidades. Es decir, que esas estrategias cooperativas plantean la consecución de finalidades que no son, principalmente, pecuniarias de finalidad personal.

Corolario. Las entidades de la Economía Social se caracterizan por un principio de acción basado en la No Prioridad en el Ánimo de Lucro Personal (NPALP), hábito genérico que poseen los individuos activos de las organizaciones componentes de ese conjunto.

Obviamente, el principio de NPALP se cumple para el segmento no lucrativo de la Economía Social, en tanto que altruismo y filantropía anteponen la asistencia a otros o el beneficio de otros, por encima del coste personal de la acción. Si esa relación beneficio/coste supera al número de enlaces que tiene una persona, hay garantía de réplica de la actitud cooperante en cierta población, según la regla que contempla Novak (2011), y que demuestra la probabilidad de inicio de un ciclo cooperativo, el contagio de esa acción a otros grupos que generen cliques. Pero también es posible el inicio de ciclos cooperativos partiendo del segmento lucrativo de la Economía Social, tal y como demuestra la existencia de un cociente común, superior jerárquicamente, que define al conjunto. En efecto, por encima de la búsqueda de una ganancia de finalidad personal pecuniaria, que pueda sustentarse en una estrategia individualista, se tiene, al menos, la finalidad de una ganancia colectiva, basada en acciones solidarias y empáticas de los agentes que pertenecen a la organización, concretadas por el cooperativismo, el mutualismo y la inclusión social.

Conviene no confundir el principio de NPALP con el de No Distribución de Beneficios (PNDB), originario de la definición comúnmente admitida de Economía Social, y que priorizaría, utilizando la terminología miseana, un análisis del comportamiento individual sobre la cataláctica, debido a la necesaria introducción del dinero para materializar el beneficio pecuniario obtenido del mercado. Un mercado, desde una perspectiva ortodoxa, que no existe para buena parte de entidades componentes de la Economía Social.

El principio de NPALP encaja en la praxeología, en la axiomática miseana ${ }^{19}$, y en su concepción de Economía al ser un medio idóneo que utilizan los individuos en la consecución de una mayor 
satisfacción o ganancia, sea pecuniaria o no -por ejemplo, social o de felicidad-. La búsqueda de una definición de núcleo común no basada en la ganancia pecuniaria de finalidad personal-individualista se apoya en la estrategia genérica de la cooperación como válida y real, por la evidencia sobre la existencia de organizaciones que se fundamentan en este tipo de estrategias desde hace siglos, e informalmente desde que el hombre vive en grupo 0, más civilizadamente, en sociedad.

\section{4.- Desde el hábito de la NPALP a las rutinas de transferencias sociales en especie}

Las acciones de las organizaciones no lucrativas y de cooperación, asociadas especialmente a la consecución de excedente social, o también de finalidad no personalista no dineraria, sostienen que las entidades de la Economía Social funcionan bajo un mecanismo de contribuciones en vez de por uno de precios para atender al problema de asignación de los recursos -dejando aparte los principios basados en bienes públicos y fallos del mercado, que fundamentan la actuación del Sector Público en la Economía-. El mecanismo de contribuciones, bajo el principio de NPALP, no tiene como resultado el máximo beneficio, la ganancia o la satisfacción/utilidad personal. Por tanto, la consecuencia práctica de lo anterior es la emisión de Transferencias Sociales en Especie (TSE) por parte de cada entidad que compone la Economía Social que, formalmente, no son otra cosa que el reflejo estadístico de una definición extensa de bienes preferentes, ya que «...comprenden los bienes y servicios individuales proporcionados a los hogares como transferencias en especie por unidades de las Administraciones Públicas y las ISFLSH (instituciones sin fines de lucro al servicio de los hogares), tanto si se han adquirido en el mercado, como si proceden de la producción no de mercado de las unidades de las Administraciones Públicas y las ISFLSH» (Eurostat, 1996, párrafo 4.104)20. Ahora bien, las entidades de la Economía Social de mercado (cooperativas, mutuas, sociedades laborales, entidades de inclusión socio-laboral) emitirían TSE ampliadas, es decir, no contempladas en la definición de Cuentas Nacionales, y sobre las que se razona a continuación.

Si las rutinas son a las organizaciones como los hábitos a los individuos, y se considera rutina aquella acción que, finalmente repetida, proviene de la persistencia de los hábitos que caracterizan a instituciones concretas, entonces serán ejemplos de rutinas: las contribuciones voluntarias de dinero o en especie -órganos, alimentos, entre otros-, como de tiempo -voluntariado- en asociaciones y, también, las donaciones, que se añadirían al fondo fundacional en fundaciones; los cesiones de parte de salario por los trabajadores-socios en sociedades laborales, en cooperativas de trabajo asociado, o en cualquier otra en la que su empleo asalariado renuncie a parte de su remuneración con el objetivo de mantener el empleo de otros; también los diferenciales, respecto al precio de mercado, favo- 
rables al cooperativista en el precio de vivienda promovida por una cooperativa de viviendas, o sobre tipos de interés activos o pasivos, respecto al de mercado, en beneficio de los socios de la cooperativa en el caso del crédito cooperativo; así como la cesión personal pecuniario del retorno cooperativo; o los diferenciales en los precios de seguros de salud, vida o productos de ahorro y otros respecto al mercado, a través de mutualidades, entre otras manifestaciones.

Por tanto, las TSE implican un coste individual implícito, no explícito, a través de las entidades que emiten la transacción, y que queda cubierto por sus recursos, procurando una mayor provisión de bienes y de servicios -sobre todo- que componen el agregado del Consumo Final de los Hogares, y que no son parte su Gasto en Consumo Final, sino que se carga al Gasto de las entidades emisoras. En consecuencia, muchas de estas transacciones -TSE ampliadas- no están cuantificadas en los Sistemas de Cuentas Nacionales y pueden ser explicativas de cierta parte de la relativa estabilidad social en España (y en otras geografías) en esta aciaga etapa donde la pobreza monetaria y la desigualdad han aumentado.

Téngase en cuenta, además, que estas contribuciones podrían tratarse como un indicador de bienestar humano, generalmente caracterizado por su invisibilidad en las comparaciones internacionales sobre desarrollo. En otras palabras, es una alternativa factible a la propuesta convencional que considera a los precios como indicadores de escasez y de bienestar en la preocupación sobre la optimización en la asignación de los recursos, pero en favor de las asignaciones de empatía y solidaridad. Y lo es, ya que no se requiere indicador de escasez cuando no hay problema de escasez, sino redistribución o liberación de recursos, dinerarios y no dinerarios, quizá antes ociosos o reflejo de un diferencial entre "precios de mercado" y "por contribución de la Economía Social", de ciertos bienes o servicios, en beneficio de otros que los producen, o disponen de ellos para el consumo y no lo hacen -una obvia cercanía a la empatía-.

Comoquiera que fuere, esa liberación de recursos - una austeridad bien entendida- aumenta el Excedente Total de la Economía (suma del Bruto de Explotación más el Social), al incorporar actividades generadas de nuevo, antes no contempladas, y que serían cierto Ahorro Social -en buena parte Público, porque cuantificaría ciertas actuaciones tradicionalmente consideradas objeto del Sector Público, y que se cargan al Sector Privado en términos de TSE-. La evidencia para España ofrece un ejemplo de límite inferior derivado de las contribuciones de tiempo del trabajo voluntario, cifrado entre 4.900 y 6.800 millones de euros, en números redondos, aproximadamente un 0,75 por 100 del PIB español, fechando las estimaciones entre 2001 y 2005 (García Delgado, 2005 y 2009).

Pero también podrían añadirse más componentes a esa generación de Excedente Social. Por ejemplo, TSE ampliadas (TSE') emitidas por las cooperativas, basadas en una liberación de recursos debido a las diferencias entre la remuneración media pagada por las cooperativas respecto a la empleada por la Economía General, con la finalidad de mantener empleo. Así, puede considerarse la remuneración media sectorial entre 2001 y 2008, obtenida del marco de Contabilidad Nacional de España base 2000 del INE, como variable aproximada de la remuneración tendencial media del mercado, $y$ 
se puede comparar con la resultante sectorial del cooperativismo, en esa etapa y para las que han mantenido o aumentado su empleo, observando si existe una diferencia.

Para ese objetivo, se utiliza la Base de Datos del Sistema de Análisis de Balances Ibéricos (SABI, https://sabi.bvdinfo.com), que ofrece información de los balances de más de 1,2 millones de empresas españolas y más de 350.000 empresas portuguesas. La base de datos está sesgada hacia las entidades de mayor tamaño, siendo las pequeñas y micro empresas poco representativas en términos comparados. En todo caso, el sesgo puede corregirse ajustando a la estratificación efectiva ${ }^{21}$. Después se procede a realizar filtros sobre las empresas con asalariados, tanto de sociedades anónimas y limitadas, como de cooperativas en los años 2001 a 2008, así como para las empresas que se mantienen entre 2001 y 2008 en la base de datos y, de éstas, las que conservaban, al menos, el número de empleados (Cuadro 2). Se buscan diferencias significativas, "D", por rama productiva, "i","22, entre el Gasto de Personal Medio de entidades societarias y cooperativas $D_{i}=\varphi_{i}\left[G P M_{i}{ }^{S O}-G P M_{i}{ }^{C O}\right.$ ]

\section{Cuadro 2. Número de observaciones de las entidades con empleados para el cálculo de las Transferencias Sociales en Especie ampliadas de las cooperativas españolas, 2001-2008}

\begin{tabular}{|lccc|}
\hline & 2001 & 2008 & $2001 / 08$ (mantienen el empleo) \\
\hline Cooperativas & 2.490 & 2.016 & $1.928(1.204)$ \\
Sociedades Anónimas y Limitadas & 310.153 & 500.008 & $301.99(251.230)$ \\
\hline
\end{tabular}

FUENTE: Base de Datos SABI sobre los métodos expuestos en el epígrafe 4.

Al elevar la muestra a la población, ajustados los sesgos por la diferente estratificación, los diferenciales salariales de sociedades sobre cooperativas arrojan un agregado de 206,5 millones de euros en 2001 y de 187 millones de euros en 2008. Tales magnitudes serían el reflejo agregado de cierta liberación de recursos por rama productiva y, así, de una TSE' a priori, con todas las cautelas a tener en cuenta, en tanto la existencia de otros factores explicativos de las diferencias de ganancias medias por asalariado y rama productiva. Además, cabe mencionar la regularidad de los sectores Agrario, Comercio al por mayor e intermediarios, Agroindustria, Confección y Fabricación de metal como emisores de TSE', sectores de alta densidad cooperativa respecto al total de entidades que participan en la producción, al contrario que los sectores de Intermediación financiera, Material electrónico y de precisión. Finalmente, al realizar los filtros sobre las entidades que mantienen su empleo entre los años

21.- Las cooperativas españolas participan entre el 0,92 y el 0,84 por 100, entre 2001 y 2008, se hable del total de organizaciones con asalariados o del empleo asalariado (García Delgado, 2005, 2009), mientras el Directorio Central de Empresas del INE, ofrece una media de 0,72 por 100, estando la participación media de entidades con ánimo de lucro personalista en el 91,9 por 100 del total de organizaciones en esos años.

22.- Clasificación Nacional de Actividades Económicas a dos dígitos, http://www.ine.es/jaxi/menu.do?type=pcaxis\&path=/t40/clasrev\&file=inebase. 
2001 y 2008, el resultado evidencia una liberación de recursos por el cooperativismo español cifrados en una media anual de cerca de 50 millones de euros entre 2001 y 2008 (Cuadro 3).

\section{Cuadro 3. Transferencias sociales de mantenimiento de empleo anual media 2001-2008. En miles de euros de 2008}

\begin{tabular}{|lc|}
\hline Maquinaria y equipo mecánico & 30.226 \\
Agricultura, ganadería y caza & 10.741 \\
Fabricación de vehículos de motor y remolques & 3.924 \\
Producción y distribución de energía eléctrica y gas & 1.256 \\
Actividades recreativas, culturales y deportivas & 760 \\
Industria textil & 757 \\
Industria del cuero y del calzado & 608 \\
Captación, depuración y distribución de agua & 507 \\
Industria del papel & 214 \\
Transporte marítimo & 2 \\
\hline
\end{tabular}

FUENTE: Base de Datos SABI.

\section{5.- La causalidad acumulativa en el cooperativismo español y el análisis de redes}

La concepción sobre un crecimiento desequilibrador es originaria de Veblen (1919), retomada como causa de desequilibrios locales y denominada propiamente como "causalidad acumulativa" por Myrdal (1957), para formalizarse en un nivel de agregación general por Kaldor (1966). También es muy utilizado en las interpretaciones de estructuralistas latinoamericanos: entre otros, Furtado (1968, 1978), Prebisch (1963, 1981), y sus seguidores como Filippo (2007 y 2009). Aquí se pretende observar la comparativa de su diferente intensidad entre la economía general (mayormente capitalista) y la cooperativa.

En el ciclo expansivo español de la década de 2000, hasta 2007, se intensifican los emprendimientos no cooperativos en la Economía General, más abiertos al juego de la competencia y a la rentabilidad económica. En consecuencia, aumenta su empleo total y asalariado, y se observan caídas de las participaciones relativas, o densidades, del cooperativismo nacional; así, la generación de empleo cooperativo sobre el total es menor que la generación de empleo de la Economía General -1,4 por 100 de las cooperativas frente al 2,1 de la Economía General-. Sin embargo, y desde el inicio de la crisis, la destrucción de empleo sobre la población en la Economía Española es contundente (-4,4 por 100 anual 
media acumulativa al emplear cifras de Contabilidad Nacional de España (INE), produciéndose las mayores ganancias de productividad aparente del trabajo, un 2,4 por 100 de media anual acumulativa sobre la destrucción de empleo. La destrucción de empleo cooperativo es relativamente menor desde el inicio de la crisis: un -0,9 por 100 medio anual acumulativo. Tampoco debe olvidarse que la descomposición anterior incluye el crecimiento real de la productividad aparente del trabajo cooperativo, alrededor del 4 por 100 en ambas etapas, que supera al crecimiento de la productividad aparente general. Este crecimiento de la productividad aparente del trabajo se alimenta de la destrucción de empleo y del efecto composición, debido a la reducida importancia relativa de la Economía Cooperativa, lo que avanza cierta hipótesis sobre una forma de crecimiento de menor causalidad acumulativa pero atenuadora de la destrucción del empleo en momentos recesivos (Cuadro 4).

\section{Cuadro 4. Descomposición aproximada del crecimiento anual medio acumulativo de la productividad aparente del trabajo española, 1999-2010. Crecimientos porcentuales}

\begin{tabular}{|l|c|cc|}
\hline \multicolumn{2}{|l|}{} & $1999-2007$ & $2007-2010$ \\
\hline $\begin{array}{l}\text { (A) Productividad aparente del trabajo } \\
\text { (VAB/Empleo)=(1)+(2)+(3) }\end{array}$ & $\begin{array}{c}\text { Nominal } \\
\text { Real (a) }\end{array}$ & $\begin{array}{c}4,0 \\
0,83\end{array}$ & 4,2 \\
\hline (VAB/VAB Cooperativo)(1) & $-2,0$ & $-2,4$ \\
\hline $\begin{array}{l}\text { Productividad aparente del trabajo de las cooperativas } \\
\text { (VAB Cooperativo /Empleo Cooperativo)(2) }\end{array}$ & $\begin{array}{c}\text { Nominal } \\
\text { Real(a) }\end{array}$ & 7,2 & 5,8 \\
\hline $\begin{array}{l}\text { Generación de empleo cooperativo sobre el empleo total } \\
\text { (Empleo Cooperativo /Empleo)(3) }\end{array}$ & 1,1 & 4 \\
\hline $\begin{array}{l}\text { (B) Generación de empleo sobre la Población } \\
\text { (Empleo/Población) }\end{array}$ & 2,1 & $-0,9$ \\
\hline $\begin{array}{l}\text { PIB por habitante } \\
\text { (PIB/Población)=(A)+(B)+(Crecimiento PIB/VAB) }\end{array}$ & Rominal & 6,2 & $-4,4$ \\
\hline
\end{tabular}

Notas: (a) Crecimiento real=Crecimiento nominal-Inflación. FUENTES: Base de Datos de la Economía Social (www.meyss.es), Contabilidad Nacional de España (INE, www.ine.es).

Por otra parte, el Análisis de Redes de las Relaciones Intersectoriales, tanto para la Economía General como para la Economía Cooperativa, necesita la aplicación del método RAS ${ }^{23}$ sobre las Tablas Input Output de la Economía Española. Se asumen los supuestos del modelo de Leontief (1970) y las apreciaciones de García Muñiz y Ramos (2003) y Morillas (1983) sobre su relación con la teoría de grafos. También se propone que los nodos-sectores productivos como elementos impregnados de cier-

23.- Idea original de Stone (1961) para la construcción de una TIO regional a partir de TIO nacional, que se utiliza para construir la TIO de un componente trasversal -segmento cooperativo- del conjunto, y no local. 
tos hábitos: basados unos en el principio de maximización de la utilidad o beneficio pecuniario personal, al tratar a la Economía General, y otros en el principio de NPALP, cuando se represente al segmento cooperativo.

A partir de las matrices de relaciones intersectoriales se procede a su conversión en matrices de adyacencia, que expresan las relaciones intersectoriales significativas, para construir con ellas los grafos y calcular la consistencia y vertebración de la Economía General y de la Cooperativa, introduciendo la idea de centralidad de Freeman (1979); donde un nodo (sector productivo) adquiere el protagonismo de las relaciones en su conjunto si se relaciona con todos los demás, distinguiendo entre "centralidad de los nodos" y la "centralidad del grafo", que Hanneman y Riddle (2005) extienden en sus formas de cálculo. La medida más simple e intuitiva de centralidad es a través del grado o número de relacio$n^{n} s^{24}$ de los nodos -sectores- del grafo - de la red de relaciones intersectoriales-; será tanto central cuanto mejor conectado esté con los demás nodos -sectores- de su entorno. También se puede intentar establecer hasta qué rama -nodo- la red de relaciones intersectoriales -el grafo- es o no una estructura centralizada, y para lo que ayudan tres indicadores: densidad, es decir, la relación porcentual del número de relaciones entre el total de las posibles; la cohesión, definida en teoría de redes como el esfuerzo de relacionarse entre nodos ramas productivas y, así, determinar el número de relaciones en el camino más corto entre ambos; y el grado de centralización-Network Centralization Index-, que es la variabilidad en grados como porcentaje de la máxima centralización. Estos indicadores se interpretan como resúmenes de la importancia de los sectores en la configuración general de las transacciones intersectoriales bajo un enfoque diferente. Los cálculos se obtienen con el software UCINET 6 (Borgatti, Everett y Freeman, 2002).

Así, el cooperativismo señala como ramas centrales y motoras a las Primarias, de Comercio, reparaciones y hostelería e Intermediación Financiera, mientras que las de Manufactura, Energía, y el sector Inmobiliario y de servicios a empresas juegan ese papel en la Economía Nacional. En cuanto a los sectores cooperativos que se ven arrastrados intersectorialmente, destacan el Primario y de la Energía, caracterizado por una escasa representación cooperativa. Debe añadirse que la Economía Nacional mantiene como compradores principales de inputs intermedios a las ramas de Energía, Inmobiliarias y servicios a empresas y las de Comercio, reparaciones y hostelería (Cuadro 5).

Por otra parte, en cuanto a la concentración de la red -centralización como indicador conjunto-, destaca inicialmente una mayor densidad en la Economía General respecto a la del segmento cooperativo; densidad que reduce mientras que la de las cooperativas aumenta. Esto manifiesta el poder de centralidad de la Manufacturas en la Economía General, y que toma posiciones (aumenta) en el segmento cooperativo. Paralelamente se percibe el cambio estructural del sector Agrario, que va perdiendo centralidad en la Economía General en el siglo XXI, y que aumenta su influencia intersecto-

24.- El grado se formaliza como ki= $\sum$ jaij, siendo "aij" los elementos los elementos de la matriz de adyacencia "A". En un grafo dirigido existirían grado de entrada al nodo (por columna) y de salida al mismo (por fila). 
rial en el segmento cooperativo. Mientras tanto, Construcción, Inmobiliarias y servicios a empresas y el sector Financiero de mercado también toman posiciones de intermediación (nodos que se localizan entre uno inicial y final) para Economía General y cooperativa, y que reflejan bien el modelo productivo gestado hasta la crisis. El cooperativismo va a participar también de la inercia de ese modelo, en los sectores que han resultado ser más sensibles y dañados por la reciente recesión en España, a través de las cooperativas de viviendas y de crédito. Conviene añadir que las últimas sufren las turbulencias propias del sector bancario, aunque no en la magnitud destructiva que ha afectado a otras entidades del sector, por diferentes prácticas de asunción de riegos. Con todo, el sector de la Construcción no aparece como destacado en la centralidad de la red intersectorial cooperativa, más concentrado en la red de la Economía General (Cuadro 5).

\section{Cuadro 5. Grado de centralidad de Freeman de las ramas productivas(a) 2000-2008}

\begin{tabular}{|l|cccccccccc|c|c|cccccccccc|c|}
\hline 2000 & Sector & 8 & 5 & 1 & 2 & 3 & 6 & 7 & 4 & 9 & $\mathrm{NCI}(\mathrm{b})$ & 2000 Red & Sector & 2 & 3 & 1 & 8 & 5 & 6 & 7 & 4 & 9 & $\mathrm{NCI}(\mathrm{b})$ \\
Red & Out Degree & 5 & 2 & 1 & 1 & 0 & 0 & 0 & 0 & 0 & 44,3 & Economía & Out Degree & 6 & 2 & 1 & 1 & 1 & 1 & 1 & 0 & 0 & 73,2 \\
Coop. & In Degree & 0 & 1 & 3 & 3 & 0 & 1 & 1 & 0 & 0 & 32,1 & Nacional & In Degree & 6 & 1 & 1 & 0 & 1 & 2 & 1 & 1 & 0 & 72,1 \\
\hline 2008 & Sector & 2 & 8 & 1 & 5 & 6 & 4 & 3 & 7 & 9 & $\mathrm{NCI}(\mathrm{b})$ & 2008 Red & Sector & 2 & 7 & 3 & 8 & 6 & 1 & 5 & 4 & 9 & $\mathrm{NCI}(\mathrm{b})$ \\
Red & Out Degree & 4 & 3 & 2 & 1 & 1 & 1 & 0 & 0 & 0 & 52,8 & Economía & Out Degree & 5 & 4 & 3 & 3 & 2 & 1 & 1 & 1 & 0 & 44,7 \\
Coop. & In Degree & 4 & 2 & 1 & 2 & 0 & 2 & 0 & 1 & 0 & 42,8 & Nacional & In Degree & 6 & 2 & 0 & 2 & 0 & 0 & 4 & 3 & 3 & 60,7 \\
\hline
\end{tabular}

Notas: (a) No son matrices de coeficiente interiores al carecer de información relevante para su estimación. Los sectores o ramas productivas son 1. Agricultura, selvicultura y pesca, 2.Manufacturas, 3.Energía y extracción, 4.Construcción, 5.Comercio, reparaciones y hostelería, 6. Transporte y comunicaciones, 7.Inmobiliario y servicios a empresas, 8.Intermediación Financiera, y 9.Educación, actividades sanitarias, sociales y otras. (b) Network Centralization Index (grado de centralización, en \%).

FUENTES: Base de Datos de la Economía Social (www.meyss.es), Contabilidad Nacional de España (INE, www.ine.es), y Borgatti, Everett, y Freeman (2002): Ucinet 6 for Windows.

En definitiva, la representación de las redes de relaciones intersectoriales muestra grafos más densos y más cohesionados de la Economía General, más vertebrados. Los indicadores que evalúan al grafo como un todo confirman lo mismo: mayor cohesión y densidad de las redes de la Economía General en comparación a las del cooperativismo (Cuadro 6 y Gráficos 3 a 6), que repercute de manera diferente en los momentos recesivos de los dos ámbitos. 


\section{Cuadro 6. Densidad y cohesión de las redes de relaciones intersectoriales en España 2000-2008}

\begin{tabular}{|l|cc|cc|cc|}
\hline & \multicolumn{2}{|c|}{2000} & \multicolumn{2}{c|}{2005} & \multicolumn{2}{c|}{2008} \\
\hline \multirow{3}{*}{ Densidad } & Cooperativas & Economía Gral. & Cooperativas & Economía Gral. & Cooperativas & Economía Gral. \\
Cohesión & 0,16 & 0,25 & 0,23 & 0,30 & 0,27 & 0,37 \\
& 0,12 & 0,33 & 0,31 & 0,44 & 0,5 & 0,43 \\
\hline
\end{tabular}

FUENTES: Base de Datos de la Economía Social (www.meyss.es), Contabilidad Nacional de España (INE, www.ine.es), y Borgatti, Everett, y Freeman (2002): Ucinet for Windows.

En consecuencia, una explicación institucionalista queda implícita en las diferencias estructurales de las relaciones intersectoriales. Las cooperativas, como instituciones formales de la Economía Social, actúan bajo el principio de NPALP. Un hábito cuyo resultado se relaciona con una menor polarización en la actividad productiva y que se evidencia aquí a través de las diferencias de configuración entre sus redes intersectoriales y las de la Economía General, formadas por nodos que persiguen un ánimo de lucro de finalidad personal. Así, el principio de NPALP es el reflejo de un hábito que fundamenta qué es la Economía Social y explica la diferente dinámica económica seguida por los dos ámbitos de organización productiva discutidos. Lo que constata una suerte de causalidad acumulativa (polarización económico-productiva) basada en las diferentes redes estructurales intersectoriales.

\section{Gráfico 3. La red de relaciones intersectoriales de las cooperativas españolas en 2000}

ENERGÍA E INDUSTRIAS EXTRACTIVAS

CONSTRUCCIÓN

EDUCACIÓN, ACT. SANITARIA, VETERINARIAS Y SOCIALES

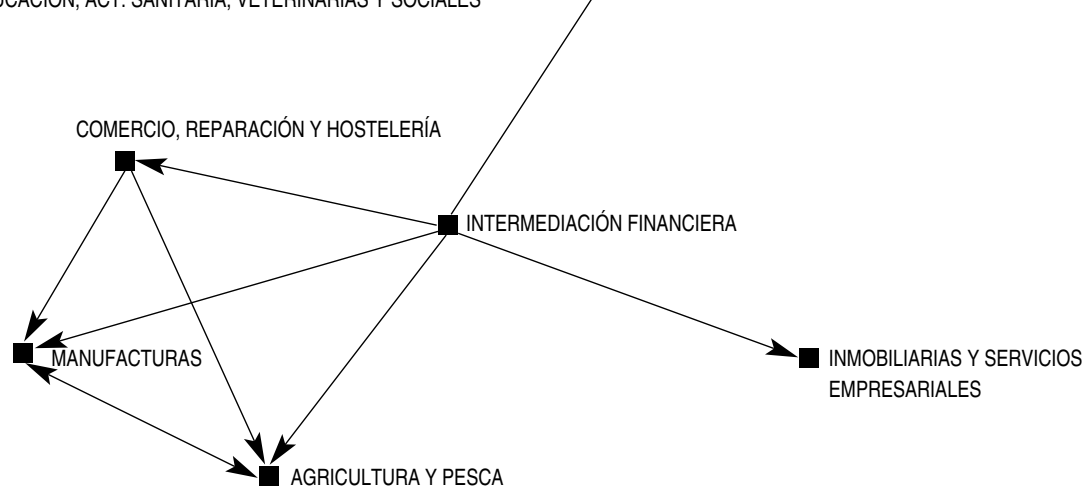

FUENTES: Igual que Cuadro 6 y Borgatti (2002): Netdraw. 


\section{Gráfico 4. La red de relaciones intersectoriales de la Economía Española en 2000}

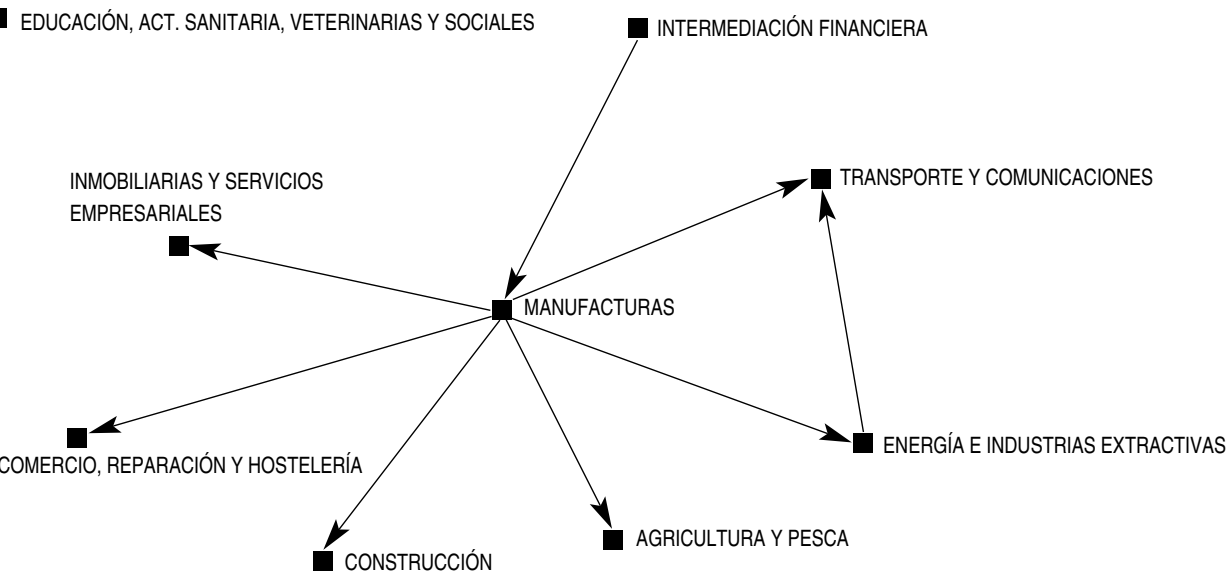

FUENTES: Igual que Cuadro 6 y Borgatti (2002): Netdraw.

\section{Gráfico 5. La red de relaciones intersectoriales de las cooperativas españolas en 2008}

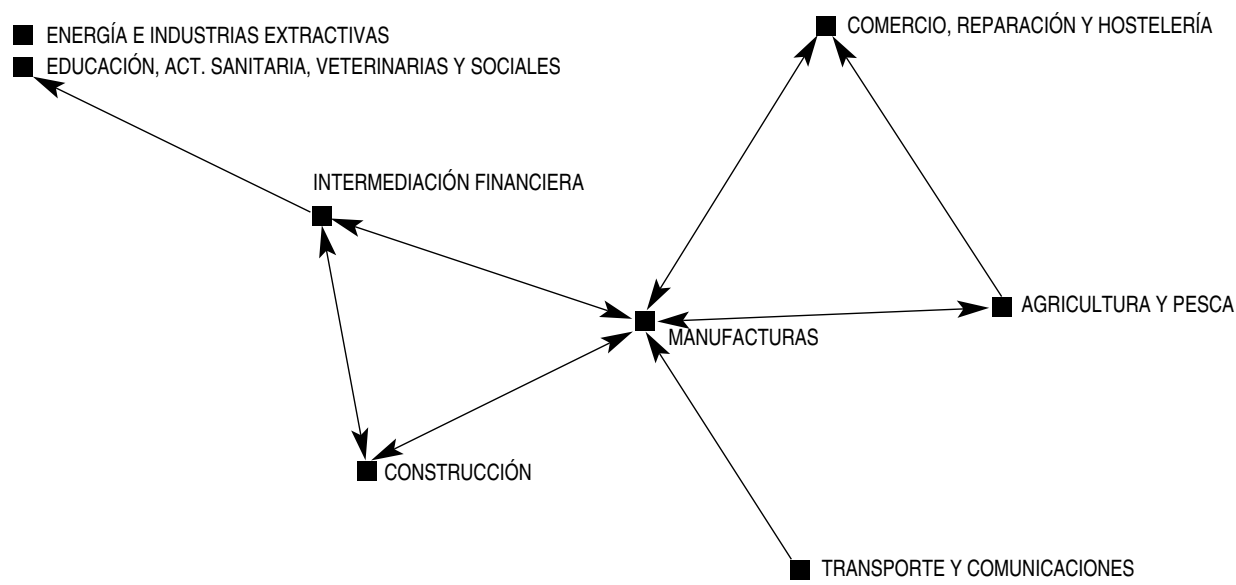

FUENTES: Igual que Cuadro 6 y Borgatti (2002): Netdraw. 


\section{Gráfico 6. La red de relaciones intersectoriales de la Economía Española en 2008}

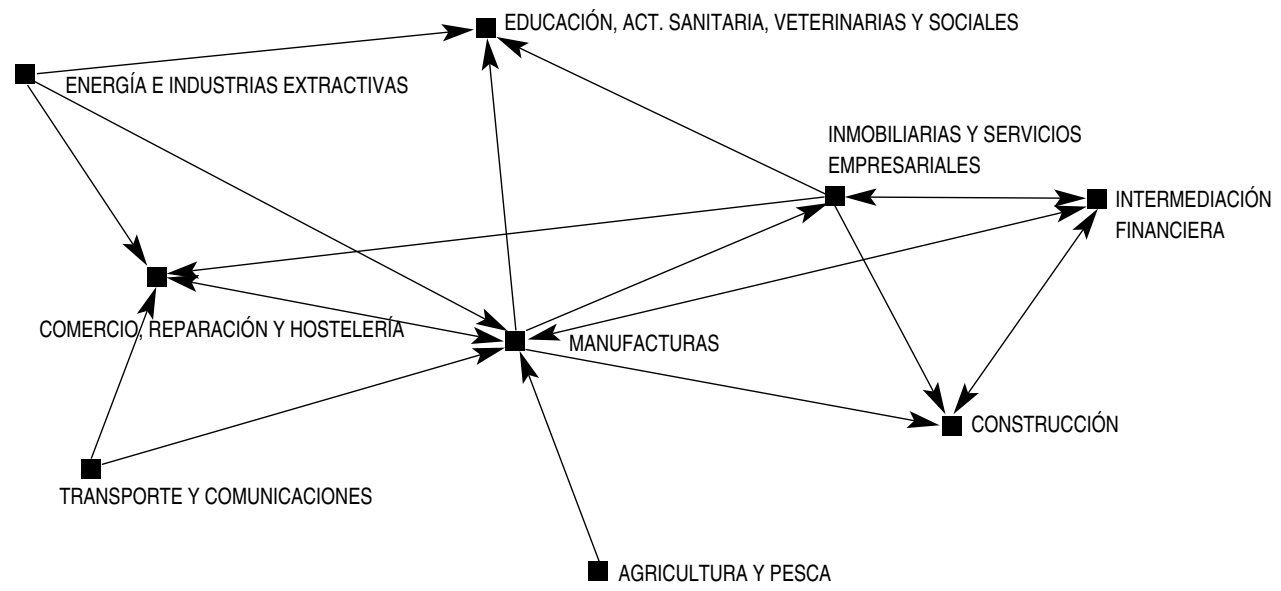

FUENTES: Fuentes: Igual que Cuadro 6 y Borgatti (2002): Netdraw.

\section{6.- Conclusiones}

El trabajo propone avanzar en el conocimiento sobre "qué es" la Economía Social, desde una concepción institucionalista, que apela a un mayor esfuerzo para solventar las limitaciones sobre las fuentes estadísticas disponibles que dificultan la tarea de visibilizarla. La definición se basa en principios comunes a sus entidades componentes y a los valores que comparten, pese a ciertas evidencias sobre restricciones de carácter académico, económico y político, asociadas a las de percepción, habida cuenta de la complejidad de la realidad humana y social, y a la indisoluble existencia humana con el lenguaje.

No obstante, puede sostenerse que las relaciones generadas por y entre los actores de la Economía Social siguen el principio de No Prioridad en el Ánimo de Lucro Personalista (NPALP), que motiva plantear la variable relacional para profundizar en el estudio de los factores que definen a las entidades de la Economía Social, ofreciendo posibilidades de avance en el estudio sobre los principios comunes, no complementarios, de sus componentes.

En consecuencia, los cinco mecanismos de cooperación descritos en el trabajo: altruismo, filantropía, cooperativismo, mutualismo e inclusión o inserción socioeconómica y laboral de colectivos en 
riesgo de exclusión, concluyen que hay un principio denominador común de No Prioridad en el Ánimo de Lucro Personal en las instituciones formales componentes de la Economía Social.

Por otro lado, estas entidades siguen una pauta institucional evolutiva desde los hábitos hasta las instituciones formales que son, y otra adaptativa a través de la persistencia en las funciones económicas que ejercen. De ahí la diversidad de configuraciones locales. Paralelamente, formalizada una organización de la Economía Social en la que sus actores procedan bajo el principio de prioridad en el ánimo de lucro personalista, la institución tenderá a extinguirse al no formalizarse en coherencia con sus hábitos constitutivos.

La Economía Social soluciona el problema de la asignación de los recursos bajo los mecanismos de su liberación (austeridad-redistribución) y de las contribuciones a través de las funciones económicas realizadas a través de sus entidades, y no por el mecanismo de los precios.

Además de cierta evidencia sobre TSE no cuantificadas en los Sistemas de Cuentas Nacionales, que obtendrían cierto Excedente Social (entre los 4 y 7 mil millones de euros en España entre 2000 y 2005), también se puede avanzar en la medida de rutinas similares (TSE ampliadas) del segmento Lucrativo de la Economía Social. Para la Economía Española una media de 50 millones de euros anuales por parte del cooperativismo español entre 2000 y 2008 con el objetivo de mantener el empleo.

Para el caso español se contrasta el principio de causalidad acumulativa, explicativo de la polarización económica, más intensa para las redes de relaciones intersectoriales que actúan en el sistema convencional, capitalista, basado en el mecanismo de los precios, y menos intensa para los esquemas de relaciones económico-productivas que actúan en el ámbito de la Economía Social, que sigue el hábito de NPALP como regla fundamentada en la evolución del hábito de reciprocidad y en la búsqueda de un beneficio colectivo. Así, la diferencia estructural entre cooperativas y entidades societarias, por sectores productivos, apuntala una diferencia de la causa adaptativa, o institucional-evolutiva, del segmento Lucrativo de la Economía Social en caso español. En efecto, los sectores con gran peso cooperativo, como Primario o Construcción ("Motor" cooperativo en 2008) confirman una adaptación inercial del cooperativismo hacia la actividad inmobiliaria, que aceleraban las entidades tradicionales societarias. Además, la diferencia de cohesión y densidad entre las redes de relaciones intersectoriales cooperativas y las de la Economía General, en la primera década de 2000, evidencia empíricamente la causalidad acumulativa como explicación institucional, basada en su distinta vertebración.

En consecuencia, no se trata de que la Economía Social genere más actividad económica comparativamente, sino que la destruye con menos facilidad en momentos recesivos. Lo anterior se comprueba también mediante la observación de cambios en la dinámica de los multiplicadores sectoriales, constatando la causa institucional como razón de ser del cooperativismo y, así, de la Economía Social, que manifiesta hábitos relacionales de empatía que suavizan los resultados económicos que arrojan los ciclos recesivos, complementando el conjunto de emprendimientos. 
Por tanto, la Economía Social resulta ser un conjunto de relaciones persistentes de empatía (redes de hábitos, instituciones), formalizadas en entidades productoras de bienes y servicios, que tienen como principio común la NPALP y emiten TSE. Se trata de entidades que tienen una prioridad de valores altruistas, filantrópicos, cooperativistas, mutualistas y de promoción de inclusión socioeconómica y laboral, por encima del beneficio pecuniario de finalidad personal. Las relaciones de empatía pueden ser interpersonales, tanto dentro de las mismas instituciones, como fuera de ellas, interinstitucionales. Y, en tanto redes, pueden formalizarse en grafos. Lo anterior, siempre con todas las salvedades a tener en cuenta en la acotación teórica propuesta y en las limitaciones de información que configuran la evidencia empírica; cuestiones recurrentes para seguir avanzando y perfilando tanto el conjunto como las posibles líneas a seguir estudiando en relación a la propuesta presentada en estas páginas.

\section{Bibliografía}

ALARCÓN, M.A. (2011): "Incidencia de la Economía Social y Solidaria en las Cuentas Nacionales. Hacia una identificación de su necesidad y un mapeo de la experiencia europea". En: Fernández Álvarez, J.F. (Ed): Innovación y Economía social y solidaria, Soporte y diseño, Barranquilla, Colombia.

ALARCÓN, M.A., CASTRO, L.M. \& RODRíGUEZ, N. (2016): Metodología para la Construcción del Sistema de Cuentas Nacionales del Sector de Economía Solidaria en Colombia, [Documento de trabajo del Proyecto "Impacto social y económico del cooperativismo en Colombia"], Centro de Investigaciones sobre el Cooperativismo, Bogotá.

ALARCÓN, M.A. ( 2016): Las Cuentas del Cooperativismo de Colombia. Magnitudes cuantitativas e impacto económico 2003-2010, [Informe Final del Proyecto "Impacto social y económico del cooperativismo en Colombia", Centro de Investigaciones sobre el Cooperativismo, Bogotá.

AMín, A. (Ed.) (2009): The Social Economy: International perspectives on Economic Solidarity, Zed Books, Nueva York.

BARABASI, A.L. (2002): Link, Perseus Publishing, Cambridge

BAREA, J. (1990): "Conceptos y agentes de la Economía Social", CIRIEC-España, Revista de Economía pública, social y cooperativa, 8, 109-117.

BAREA, J. \& MONZÓN, J.L. (Dirs.) (1992): Libro Blanco de la Economía Social en España, Ministerio del Trabajo y Seguridad Social, Madrid. 
BAVELAS, A. (1948): "A mathematical model for group structure", Human Organizations, 7, 16-30.

BERTALANFFY, L.V. (1993): Teoría general de los sistemas: fundamentos, desarrollo, aplicaciones, Fondo de Cultura Económica, México D.F.

BONACICH, P. (1987): "Power and centrality: A family of measures", American Journal of Sociology, $92(5), 1170-1182$.

BORGATTI, S.P. (2002): NetDraw: Graph Visualization Software, Analytic Technologies, Harvard.

BORGATTI, S.P., EVERETT, M.G. \& FREEMAN, L.C. (2002): Ucinet for Windows: Software for Social Network Analysis, Analytic Technologies, Harvard, MA.

BORZAGA, C. \& DEFOURNY, J. (2001): The emergence of social enterprise, Library of congress cataloging in publication data, Londres.

BRIDGE, S., MURTAGH, B. \& O'NEILL, K. (2009): Understanding the social economy and the third sector, Palgrave Macmillan, Londres.

CHAVES, R. (1999): "La Economía Social como enfoque metodológico, como objeto de estudio y como disciplina científica", CIRIEC-España, Revista de Economía Pública, Social y Cooperativa, 22, 115-139.

CHAVES, R., MONZÓN, J.L., PÉREZ DE URALDE, J.M. \& RADRIGÁN, M. (2013): "La Economía Social en clave internacional. Cuantificación, reconocimiento institucional y visibilidad social en Europa, Iberoamérica y Norte de África", REVESCO, Revista de Estudios Cooperativos, 112 Extraordinario en Homenaje al Profesor Alfonso Carlos Morales Gutiérrez, 112-150.

CIIAC (CENTRO DE INVESTIGACIÓN, INFORMACIÓN y APOYO A LA CULTURA, A.C.) (2003): "Desarrollo Económico y bienes relacionales. Primera aproximación teórica". Traducción de Fondazione Giacomo Brodolini (1997): "Sviluppo economico e beni relazionali: una prima ricognizione teorica". Economia y lavoro. Enero-Junio 1-2, MASILIO EDITORI, POR SAVIÑON, A., DÍAZ, M.A. y REVILLA, R. por Editorial Schola, México.

COASE, R.H. (1992): "The Institutional Structure of Production", American Economic Review, 82 (4), 713-719.

COLEMAN, J.S. (1988): "Social capital in the creation of human capital", American Journal Sociology, 94 (Supplement), S95-S120.

COLEMAN, J.S. (1990): Foundations of Social Theory, Harvard University Press, Cambridge (Massachusetts).

COMISIÓN BRUNDTLAND (1987): Nuestro Futuro Común, Oxford University Press, Oxford.

CORAGGIO, J.L. (1997): "Alternativas para o desenvolvimiento humano en un mundo globalizado", Revista Proposta (Fase), 72, 30-38. 
CORAGGIO, J.L. (2002): "La propuesta de Economía solidaria frente a la Economía neoliberal". Exposición realizada en la Conferencia sobre Economía Solidaria dentro del Eje I: La producción de riquezas y la reproducción social, del Foro Social Mundial, Porto Alegre, 31 enero a 5 febrero, http://www.coraggioeconomia.org//lc/archivos\%20para\%20descargar/CHARLAS,\%20CONFERENCIAS, \%20DISCURSOS/JLC\%20-\%20Foro\%20Social\%20Mundial.pdf

CORAGGIO, J.L. (2009): "Los caminos de la Economía social y solidaria", Iconos. Revista de Ciencias Sociales, Facultad Latinoamericana de Ciencias Sociales-Sede Académica de Ecuador, 33, 2938.

DEFOURNY, J. (1992): "Orígenes, contextos y funciones de un Tercer Gran Sector". En: Monzón, J.L. y Defourny, J. (1992): Economía Social. Entre economía capitalista y economía pública, CIRIECEspaña, Valencia.

DEFOURNY, J. \& DEVELTERE, P. (1999): "The social economy: the worldwide making of a third sector". En: Defourny, J., Develtere, P. \& Fonteneau, B. (Eds.), L'économie sociale au Nord et au Sud.

DEFOURNY, J., FAVREAU, L. \& LAVILLE, J. (Dirs.) (1997): Inserción y nueva Economía Social, CIRIEC-España, Valencia, 335-355.

DEFOURNY, J. \& NYSSENS, M. (2012): "El enfoque EMES de empresa social desde una perspectiva comparada", CIRIEC-España, Revista de Economía Pública, Social y Cooperativa, 75, 734.

ECHEVERRÍA, R. (2008): Ontología del lenguaje, Granica, Buenos Aires.

EUROSTAT (1996): Sistema Europeo de Cuentas Económicas. Oficina de publicaciones de Luxemburgo, http://europa.eu/legislation_summaries/budget/34005_es.htm

FAJARDO, I.G. (2016): "Social Economy enterprises: aims and principles". In: Cuypers, D., Coates, A., \& Vallet, N. (Eds), Social economy on the move. Legal aspects, Publicatie Die Keure, Brujas.

FELBER, C. (2012): La economía del bien común, Ed. Deusto, Barcelona

FREEMAN, L.C. (1979): "Centrality in Social Networks. Conceptual Clarification", Social Networks, 1, 215-239.

FILIPPO, A. (2007): "La Escuela Latinoamericana del Desarrollo: tensiones epistemológicas de un movimiento fundacional", Cinta de Moebio: Revista electrónica de epistemología de ciencias sociales, Universidad de Chile, Santiago de Chile, http://www.uchile.cl/29/difilippo.pdf

FILIPPO, A. (2009): "Estructuralismo latinoamericano y teoría económica", Revista CEPAL, 98.

FURTADO, C. (1968): Teoría y política del desarrollo económico, Siglo XXI, México, D.F.

GAIGER, L.I. (1999): "La solidaridad como una alternativa económica para los pobres", CIRIECEspaña, Revista de Economía Pública, Social y Cooperativa, 31, 186-205. 
GAIGER, L.I. (2004): "Sentido e viabilidade das formas de produção não capitalistas: alguns resultados de pesquisa sobre a ESOL no Brasil", Sixth International Conference International Society For Third-Sector Research, Toronto (http://www.tau.org.ar).

GAIGER, L.I. (2007): "La Economía Solidaria y el capitalismo en la perspectiva de las transiciones históricas". En: Coraggio, J.L. (Org.), La Economía Social desde la periferia. Contribuciones latinoamericanas, Colección lecturas sobre Economía Social, Altamira, Buenos Aires.

GAIGER, L.I. (2008): "A dimensão empreendedora da economia solidária: notas para um debate necessário", Otra Economía, v. II, n. 3, julio/diciembre.

GANDLGRUBER, B. (2007): "Procesos de Evolución de sistemas institucionales. Contribuciones de Geoffrey M. Hodgson a la teoría de la empresa". En: Taboada Ibarra Eunice (Coord.), Hacia una nueva teoría de la empresa. Elementos desde la teoría Económica contemporánea, Eon, México.

GANDLGRUBER, B. (2010): Instituciones, coordinación y empresas. Análisis económico más allá de mercado y estado, Anthropos, Universidad Autónoma de México, Unidad Cuajimalpa, México.

GARCÍA DELGADO, J.L. (Dir.) (2004): Las cuentas de la Economía Social. El Tercer Sector en España, Thomson Civitas-Fundación FONCE, Madrid.

GARCÍA DELGADO, J.L. (Dir.) (2005): La Economía Social en España. Volumen (I). Un enfoque económico del Tercer Sector, Fundación FONCE, Madrid.

GARCÍA DELGADO, J.L. (Dir.) (2009): Las cuentas de la Economía Social. Magnitudes y Financiación del Tercer Sector en España 2005, Editorial Aranzadi, Madrid.

GARCÍA MUÑIZ, A.S. \& RAMOS, C. (2003): "Las redes sociales como herramienta de análisis estructural input-output", Revista hispana para el análisis de redes sociales, 4.

HANNEMAN, R.A. \& RIDDLE, M. (2005): Introduction to social network methods, University of California, Riverside, http://faculty.ucr.edu/ hanneman/

HODGSON, G. (1993): "Transaction Costs and the Evolution of the Firm". In: C. Pitelis (Ed.), Transaction Costs, Markets and Hierarchies. Critical Assessments, Basil Blackwell, Oxford, 77-100.

HODGSON, G. (1993): "Institutional Economics: Surveying the Old and the New", Metraeconomica, 44 (1), 1-28.

HODGSON, G. (1999): Evolution and Institutions: On Evolutionary Economics and the Evolution of Economics, Edward Elgar, Cheltenham.

HODGSON, G. (2000): "What is the essence of Institutional Economics?", Journal of Economic Issues, 34 (2), 317-29.

HODGSON, G. (2001): How Economics Forgot History. The Problem of Historical Specifity in social Science, London and New York: Routledge. 
HODGSON, G. (2004): "Opportunism is Not the Only Reason Why Firms Exist: Why an Explanatory Emphasis on Opportunism May Mislead Management Strategy", Industrial and Corporate Change, 13 (1), 403-20.

HUDSON, R. (2009): "Life on the edge: navigating the competitive tensions between the social and the economic in the social economy and in its relations to the mainstream", Journal of Economic Geography, 9 (4), 493-510.

KALDOR, N. (1966): Causes of the Slow Rate of Economic Growth of the United Kingdom. An Inaugural Lecture, Cambridge, Cambridge University Press.

KOSCHATZKY, K. (2002): "Fundamentos de la Economía de redes. Especial enfoque a la innovación", Economía Industrial, 346, 15-26.

LEONTIEF, W. (1970): El análisis económico input-output (ed.1966), G. Gili, Barcelona.

LÓPEZ, F. (2005): Las raíces históricas del Tercer Sector, Documento de trabajo 1/2004 de la serie La Economía Social en España, FONCE.

MISES, L.V. (1980, edición 1986): La acción humana. Tratado de Economía, Unión Editorial, Traducido del original The Human Action de 1949 por Joaquín Reig Albiol.

MONZÓN, J.L. (2006): "Economía Social y conceptos afines: fronteras borrosas y ambigüedades conceptuales del Tercer Sector", CIRIEC-España, Revista de Economía Pública, Social y Cooperativa, 56, 9-24.

MONZÓN, J.L. (Dir.) (2010): Las grandes cifras de la economía social, 2008. CIRIEC-España, Valencia.

MONZÓN, J.L. \& CHAVES, R. (2007): La Economía social en la Unión Europea, №. CESE/COMM/05/2005, Comité Económico y Social Europeo (CESE), Bruselas.

MONZÓN, J.L. \& CHAVES, R. (2012): La Economía social en la Unión Europea, Comité Económico y Social Europeo (CESE), Bruselas.

MORAIS, L.P. et a. (2010): Economía Social y Solidaria: construyendo un entendimiento común, Documento de trabajo 2010, Centro Internacional de Formación de la Organización Internacional del Trabajo, Turín.

MORAIS, L.P. \& BACIC, M.J. (2009): "Economía Social y Solidaria y políticas públicas en Brasil: notas preliminares", ANAIS do 53 ICA, México (CD ROM).

MORAIS, L.P. \& BACIC, M.J. (2008): "Economía Social y programas de emancipación por medio de emprendimientos sociales en Brasil: los avances y las dificultades actuales", $27^{\circ}$ Congreso Internacional de CIRIEC, Sevilla. (CD ROM).

MORILLAS, A. (1983): La Teoría de grafos en el Análisis Input-Output. La estructura productiva andaluza, Universidad de Málaga, Málaga.

MYRDAL, G. (1957): Economic Theory and Underdeveloped Regions, Duckworth, Londres. 
MYRDAL, G. (1968): Asian Drama. An Inquiry Into the Poverty of Nations, Vol. I-III, Pantheon, Nueva York.

NACIONES UNIDAS (2003): Manual de la ONU sobre Entidades No Lucrativas en el Sistema de Cuentas Nacionales 1993, Nueva York.

NORTH, D.C. (1995): Instituciones, Cambio Institucional y Desempeño Económico, FCE, México D.F.

NOOTEBOOM, B. (2000): Learning and Innovation in Organizations and Economics, Oxford University Press, Oxford.

NOOTEBOOM, B. (2002): Trust - Forms, Foundations, Functions, Failures, Edward Elgar, Cheltenham.

NOOTEBOOM, B. (2003): "Governance and Competence: How can they be combined?", Cambridge Journal of Economics, 28 (4), 505-525.

NOVAK, M. \& HIGHFIELD, R. (2011): Supercooperadores, Ediciones B, Barcelona.

NOYA, A. \& CLARENCE, E. (2007): The social economy: building inclusive economies, OECD, París.

PÉREZ DE MENDIGUREN, J.C. et al. (2009): "Economía Social, Empresa Social y Economía Solidaria: diferentes conceptos para un mismo debate", Papeles de Economía Solidaria, 1, REAS Euskadi, Bilbao.

POTTS, J. (2000): The New Evolutionary Microeconomics. Complexity, Competence and Adaptive Behavior, Edward Elgar, Cheltenham.

POTTS, J. (2001): "Knowledge and Markets", Journal of Evolutionary Economics, 11 (4), 413-32.

PREBISCH, R. (1963): Hacia una dinámica del desarrollo latinoamericano, Fondo de Cultura Económica, México, D.F.

PUTNAM, R. (1994): Para hacer que la democracia funcione. La experiencia italiana en descentralización administrativa, Galac, Caracas.

RUTHERFORD, M. (1994): Institutions in Economics. The Old and the New Institutionalism, Cambridge University Press, Cambridge.

SAJARDO, A. (1996): Análisis Económico del Sector No Lucrativo, Tirant lo Blanch, Valencia

SALAMON, L. et al. (2004): La sociedad civil global. Las dimensiones del sector No Lucrativo, Fundación BBVA.

SÁNCHEZ, L.A. \& PÉREZ, E. (2015): "Las entidades de economía social como protagonistas de un nuevo modelo de emprendimiento y medidas legales de apoyo al emprendimiento", CIRIECEspaña, Revista de Economía Pública, Social y Cooperativa, 84, 35-62. 
SILES, M., ROBINSON L.J. \& SCHMID, A.A. (2003): "El Capital social y la Reducción de la Pobreza - Hacia un Paradigma Maduro". En: Naciones Unidas, Cepal y Universidad del Estado de Michigan: Capital social y Reducción de la Pobreza en América Latina, en Busca de un Nuevo Paradigma, Santiago de Chile, 51-113.

SINGER, P. (2000): "A economia solidária no Brasil: a autogestão como resposta ao desemprego". En: Singer, P. y Souza, A. (Org.), A Economia solidária no Brasil, a autogestão como resposta ao desemprego, Contexto, Sao Paulo.

SINGER, P. (2007): "Economía Solidaria. Un modo de producción y distribución”. En: Coraggio, J.L. (Org.), La Economía Social desde la periferia. Contribuciones latinoamericanas, Colección lecturas sobre Economía Social, Altamira, Buenos Aires.

SOMAVIA, J. (1999): Trabajo Decente. Memoria del Director General, OIT, Ginebra. http://www.ilo.org/public/spanish/standards/relm/ilc/ilc87/rep-i.htm.

ULUORTA, H.M. (2009): The social economy: working alternatives in a globalizing era, Routledge, Abingdon.

VEBLEN, T.B. (1919): The Place of Science in Modern Civilization and Other Essays, Huebsch, Nueva York.

VEBLEN, T.B. (1994): The theory of the Leisure Class. Penguin, Nueva York.

VIAÑA, E. (2008): “¿Qué es el Tercer Sector? Teoría y alguna evidencia empírica”, Revista Asturiana de Economía, 41, 7-23.

WILLIAMSON, O.E. (2000): "The New Institutional Economics: Taking Stock, Looking Ahead", Journal of Economic Literature, 38, 595-613. 